Preprints of the

Max Planck Institute for

Research on Collective Goods

Bonn 2017/5

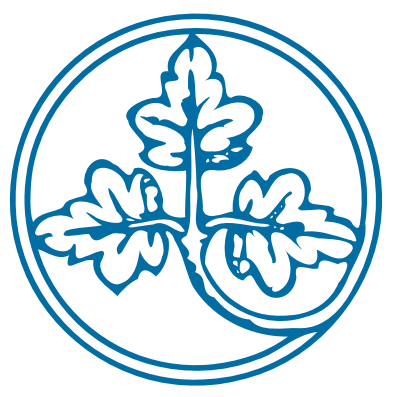

How to Protect Entitlements:

An Experiment

Oren Bar-Gill

Christoph Engel

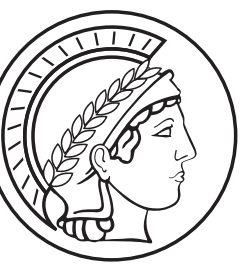




\section{How to Protect Entitlements: An Experiment}

Oren Bar-Gill / Christoph Engel

May 2017

this version: April 2018 


\title{
How to Protect Entitlements: An Experiment ${ }^{*}$
}

\author{
Oren Bar-Gill / Christoph Engel
}

\begin{abstract}
In a full-information, zero transactions costs world, the degree of protection afforded to an entitlement does not affect the likelihood of efficient trade. In reality, imperfect information is often inevitable. Specifically, a party will usually have incomplete information about fairness norms held by the other party - fairness norms that affect the other party's willingness to pay (WTP) or willingness to accept (WTA). Importantly, these fairness norms may depend on how strongly the entitlement is protected. We experimentally test the effect of the degree of protection on the parties' WTP and WTA and on the likelihood of efficient trade by varying the legal remedy for infringing upon the owner's entitlement. We show that our participants can be divided into three groups corresponding to three different fairness norms: negative types whose WTP and WTA are decreasing in the strength of the legal remedy; positive types whose WTP and WTA are increasing in the strength of the legal remedy; and flat types whose WTP and WTA do not depend on the strength of the legal remedy. We find that type is roledependent, such that a higher WTP and a lower WTA - the combination most conducive to efficient trade - is obtained with a weaker legal remedy.
\end{abstract}

JEL: C78, C91, D12, D63, K11, K12

Keywords: property rule, liability rule, damages, compensation, Coase theorem, bargaining, fairness, equality, desert, entitlement, taking

Helpful comments by Pascal Langenbach and Nan Zhang, and audiences at the Libera Università Internazionale degli Studi Sociali in Rome, the Hamburg Institute for Law and Economics, and the Max Planck Institute for Research on Collective Goods are gratefully acknowledged. 


\section{Introduction}

How should entitlements be protected? How should the law respond when Taker infringes upon Owner's entitlement? Should the law grant Owner an injunctive remedy (and perhaps impose a criminal penalty on Taker)? Or should the law only require Taker to pay damages to Owner? And, if so, how much damages? Legal orders differ widely in this respect, both in the private law (Treitel 1988) and public law (Alterman 2010) rules that address the infringement of entitlements. Extending the rational in Coase (1960), Kaplow and Shavell (1996) argued that, as long as transaction costs are low, the type and degree of protection afforded to an entitlement is irrelevant for efficiency. Even if the entitlement were only weakly protected, such that a low-valuation Taker has a credible threat to take from a high-valuation Owner, Coasean bargaining would prevent the inefficient taking. Owner would pay a "bribe" and Taker would go away. In this low-transaction-costs world, how an entitlement is protected only has distributional implications: stronger protection increases Owner's payoff and decreases Taker's payoff. The efficient outcome obtains regardless of the type and degree of protection.

These predictions even hold if either Owner or Taker, or both of them, hold non-standard preferences. If Taker knows how strongly Owner cares about distributional fairness, or about respect for ownership, she adjusts the bribe that she demands. Owner would similarly adjust his bargaining behavior in response to Taker's known non-standard preferences. Coasean bargaining presupposes that preferences are common knowledge though. Arguably, when taking well-documented behavioral regularities into account, this assumption is strong. There is a risk of error and of bias. Error is likely because fairness preferences are heterogeneous and vary in type and strength across individuals. Even worse, beliefs about a counterparty' nonstandard preferences are likely to be systematically distorted. Self-serving fairness interpretations are sustained by the erroneous belief that most everybody adheres to the same interpretation, which creates a bias. Through error and through bias, a clashing of fairness norms might prevent efficient contracting. That fairness norms interfere with Coasean bargaining is, of course, well known. Our contribution is to test how these fairness norms are affected by the type and degree of protection afforded to an entitlement. We thus study the efficiency and distributional implications of the critical policy choice how to protect an entitlement.

We conduct an experiment that randomly matches participants into groups of two, one Owner and one Taker. Owner has to earn one unit of a token good by a laborious real effort task. Her induced valuation for this good is high (48). Taker can take the good. Her valuation for the good is only half as high (24). It therefore is efficient if the good is not taken. The parties are given the opportunity to strike a deal, such that Taker gives up her ability to take the good in exchange for a bribe paid by Owner. We implement ultimatum bargaining. Owner makes an offer that Taker may accept or reject. Our treatments are within subjects. The first treatment captures the essence of a property rule: if Taker takes the good, the experimenter takes it back and returns it to Owner. The remaining six treatments correspond to a liability rule with varying levels of damages: if the good is taken, then Owner is only compensated by a monetary 
transfer of $30,24,18,12,6$ or 0 . (A transfer of 0 is equivalent to granting Taker a property right in the good.)

From a welfare perspective, our results are rather comforting. In the property rule treatment, efficiency is mechanical. We thus focus on the liability rule treatments. On average, in $77.19 \%$ of all (liability rule) cases the good stays with Owner, as is efficient. Yet, this efficient outcome can only partially be attributed to successful Coasean bargaining: the parties strike a deal in only $37.89 \%$ of the liability cases. In $23.33 \%$ of the liability cases Owner does not make an offer in the first place. And, of the $76.66 \%$ of cases where Owner makes an offer, in $50.57 \%$ the offer, i.e. Owner's willingness to pay (WTP), is below the minimum offer that Taker is willing to accept (WTA). The relatively good welfare balance is due to the fact that only $36.72 \%$ of those participants who have kept the ability to take the good act upon it.

These findings are driven by a clash in fairness norms and associated beliefs. In particular, we identify three distinct groups or types of participants:

[1] Negative types: Taker's WTA and Owner's WTP, as well as beliefs about the respective counterpart's valuations, are decreasing in the strength of the legal remedy. This group is grosso modo in line with the expectations of standard economic theory. When Owner's entitlement is more strongly protected, Taker's outside option becomes less attractive and thus Taker's WTA decreases. Also, when Owner's entitlement is more strongly protected, Owner's outside option becomes more attractive and thus Owner's WTP decreases.

Flat types: Taker's WTA and Owner's WTP do not vary with the strength of the legal remedy. This group of participants believes in the equality of outcomes. They essentially do not react to our treatment manipulation.

[2] Positive types: Taker's WTA and Owner's WTP increase with the strength of the legal remedy. For these participants, a higher degree of protection reduces the harm to Owner from a taking, such that taking becomes more acceptable. As a result, Taker demands a higher bribe to refrain from taking the entitlement (higher WTA); and Owner is willing to pay a higher bribe to prevent a taking (higher WTP).

This type heterogeneity creates informational asymmetry that explains the relatively low probability of a successful deal. In particular, with such heterogeneity it is more difficult for Owner to predict Taker's WTA and, as a result, more offers are rejected. Finally, our analysis provides guidance to policymakers tasked with determining how entitlements should be protected. Efficiency requires successful bargaining between Owners and Takers. Such bargains are more likely when Takers have lower WTA and Owners have higher WTP. We find that many Takers are positive types, whereas many Owners are negative types. Therefore, surprisingly, a weaker legal remedy can be more conducive to efficient bargaining. 
In supplementary treatments we show that this heterogeneity of the type space, and the resulting weakness of Coasean bargaining, replicate and are robust. We also verify the ironic result that owners are most vulnerable when liability for taking is highest. This vulnerability, we suggest, is a side-effect of takers' respect for property: if compensation is relatively generous, takers demand higher amounts for giving up their option to take, and are more likely to actually take the good if owners offer smaller amounts.

Our experiment speaks to three legal debates. First, we contribute to the general property rules versus liability rules debate: Is property rule protection preferable over liability rule protection? We add a behavioral perspective to this long-standing debate (Calabresi and Melamed 1972, Polinsky 1979, Krier and Schwab 1995), which for instance matters for the protection of patents (Shapiro 2016). Second, our experimental results are relevant for the decades-old debate over "efficient breach of contract" (from the rich literature see only Birmingham 1970, Goetz and Scott 1977, Friedmann 1989, Lewinsohn-Zamir 2001, Lewinsohn-Zamir 2012, Posner 2014): if the remedy for breach of contract is specific performance, contractual rights are perfectly protected; if the remedy is expectation damages, the degree of protection is potentially limited. Finally we contribute to the debate, both in contracts and in torts, over the effect of imperfect liability regimes (Epstein 2001, Gomez and Penalva 2008).

The remainder of the paper is organized as follows. Section 2 presents the design of the experiment. Section 3 places our experiment into the framework of the literature and formulates hypotheses. Section 4 reports results. Section 5 presents robustness checks and extensions deriving from our supplementary treatments. Section 6 concludes with discussion.

\section{Design}

In the main experiment, participants are randomly assigned to groups of two, one Owner and one Taker. Each of them receives an endowment, $E$, which is large enough to rule out limited liability concerns. The experiment has five stages. Participants are informed about all five stages at the beginning of the experiment.

In the first stage, one of the two group members, Owner, is given a laborious real effort task (it has for instance been used by Falk and Huffman 2007): Owner has to correctly count the number of $1 \mathrm{~s}$ in 10 tables of size 10x10 with 1 s and 0 s. In recompense, she receives a token. The experimenter pledges to buy this token from her at the end of the experiment at price $h$, should she then be in possession of the token.

In the fourth stage, Taker has the possibility to take this good. If Taker takes the good, the experimenter buys the good from her at the end of the experiment at price $l<h$. Such a taking, however, will trigger a remedy. Specifically, we test seven different remedies (namely, seven different treatments): 
1. Taker may take the good without having to pay damages $(d=0)$

2. If she takes the good, she has to pay $\mathrm{d}=1 / 4 * l$

3. $\sim d=1 / 2 * l$

4. $\sim d=3 / 4 * l$

5. $\sim d=l$

6. $\sim d=5 / 4 * l$

7. She must give the good back.

Using the strategy method (Selten 1967), in stage two we ask Owner, for each one of the seven treatments, whether she wishes to make an offer to Taker and, if so, how much she is willing to pay (WTP) to avoid a taking. In stage three, we ask Taker, for each one of the seven treatments, to report the lowest offer she would be willing to accept (WTA). We also ask him, again separately for each of the seven treatments, whether he wishes to take the good should her counterpart not make an offer, or should the offer be below the cutoff he has set. If an offer is made and accepted, a contract is concluded that will be perfectly enforced by the experimenter. In this contract, Taker gives up the right to take the good for a price (bribe) paid by Owner. This price is the Owner's stated WTP. ${ }^{1}$

At the very end of the experiment, one of the seven treatments is randomly chosen to be payoff relevant. Each situation has the same probability to be chosen. This is common knowledge. If Owner's offer is above or at the cutoff that Taker has set, the deal is struck and executed, and Owner pays the price she has stated. Otherwise the good is given to Taker, if she had (conditionally) decided to take. Then the stipulated remedy applies: the good is given back to the original owner in the first situation, or the owner receives compensation, as applicable. In the experiment we set $E=60, h=48, l=24, d \in\{0,6,12,18,24,30\}{ }^{2}$ These sums are all measured in Experimental Currency Units (ECU).

To gain insight into the cognitive and motivational effects, after the main experiment but before we give feedback about choices in the main experiment, we elicit beliefs. We ask Takers to postdict how many Owners made an offer, and the size of the offer, for each of the seven

1 Note that participants know that they have to decide before they receive feedback about their counterpart's choice and, therefore, cannot condition their own choice on the choice of their counterpart.

2 The experimental design implements an incentive-compatible elicitation of Taker's WTA, which reflects Taker's reservation price. Taker gains nothing from overstating his WTA. Indeed, if Taker reports a WTA above his true reservation price, he reduces the probability of a payoff-increasing deal without increasing the price that he gets if a deal is struck (this price is determined solely by Owner's offer). The experimental design also implements an incentive-compatible elicitation of Owner's WTP, but this WTP measure merits further clarification: In our design, Owner's WTP does not reflect Owner's reservation price (defined as the maximum amount Owner would be willing to pay, such that Owner would still prefer a deal to her outside option). Indeed, Owner would be expected to offer a price, i.e., state a WTP measure, below her reservation price. The lower price reduces the probability of a deal, but increases Owner's payoff if a deal is struck. Owner will balance these two effects, based on her beliefs about Taker's WTA. Accordingly, our design implements an incentive-compatible elicitation of Owner's WTP, as we define it, but not of Owner's reservation price. Note that this is not a limitation of internal validity, given our research question. We do not want to predict reservation prices in the population. We want to learn in which ways different remedies affect the likelihood of the welfare maximizing allocation of the good. The design is also externally valid. In the field, Owner and Taker would not know the true reservation price of their counterpart, and would have to rely on their beliefs. See also Section 4(b) below. 
situations. We ask Owners to postdict the mean offer that has been accepted. All postdictions are incentivized. ${ }^{3}$ We further administer standard tests for risk aversion (Holt and Laury 2002) and ambiguity aversion (Ellsberg 1961), and the short version of the Big5 personality inventory (Rammstedt and John 2007), and ask for demographic information. Before the beginning of the main experiment, participants have to answer control questions. They have to indicate the correct payoffs for both parties and two different regimes, provided a deal is struck, and provided there is no deal and the second participant takes the good.

The experiment was run at the Econ Lab of Hamburg University. The experiment was programmed in zTree (Fischbacher 2007). Participants were invited with hroot (Bock, Baetge et al. 2014). 190 students with various majors participated. 97 (51.05\%) were female. Mean age was 24.97. Participants on average earned $13.51 €,{ }^{4} 14.21 €$ for Owners and $12.81 €$ for Takers.

The experiment is designed to rule out several known reasons why Coasean bargaining does not yield the efficient outcome. We fix transaction costs at zero (cf. King 1994, Shogren 1998, Rhoads and Shogren 1999, Croson and Johnston 2000, Cherry and Shogren 2005). Valuations are common knowledge (cf. Prudencio 1982) ${ }^{5}$ (Hoffman and Spitzer 1982, Croson and Johnston 2000, Ayres 2005). Participants are not under time pressure (cf. Prudencio 1982, Harrison, Hoffman et al. 1987). Interaction is completely anonymous, and communication is exclusively through the negotiation protocol (cf. Hoffman and Spitzer 1982, Prudencio 1982). There is no shadow of the future, and hence no room for establishing a relationship or for reputational concerns (cf. Hoffman and Spitzer 1982, Harrison and McKee 1985). Contracts are perfectly enforced (cf. Harrison and McKee 1985).

Lab experiments are not meant to map (legal) reality. They are tools for identifying causal effects. In the interest of achieving identification, they have to narrow down the situation to a single cause that is randomly assigned and that theory predicts to have an effect. Our experiment is designed to test the effects of varying degrees of legal protection, as captured by the strength of the remedy that Owner enjoys when her asset is taken. We acknowledge that in (legal) reality, a certain type of asset or right enjoys a certain type of remedy; we generally do not observe varying remedies for the same type of asset or right. (For example, possessory interests in physical assets are generally protected by strong property rules.) Yet by holding the asset (and other aspects of the bargaining environment) fixed and varying the remedy, we are able to isolate the effect of more or less generous damages rules.

\footnotetext{
3 For further details about the experimental design, please see the instructions in the Appendix.

$4 \quad$ Which was equivalent to $\$ 14.37$ on the first day of the experiment.

5 The critique by Norton and Patrick (1985) does not concern this point.
} 


\section{Hypotheses}

\section{a) Standard Theory}

With common knowledge of rationality, participants reason backwards. If no contract hinders her and $d<l$, Taker takes the good; if $d>l$, there is no taking. Moving to the bargaining stage: If $d>l$, Taker's threat to take is not credible, and thus Owner offers nothing. If $d<l$, Taker's threat to take is credible. Taker will accept any offer larger than $l-d$; and Owner who has all the bargaining power will offer $l-d+\varepsilon$. (With $d=l$ Owner is indifferent between making an offer and not making one.) Irrespective of treatment, Coasean bargaining creates efficiency. We predict:

$\mathbf{H}_{1}$ : a) Irrespective of treatment, Owner keeps the good.

b) If Owner can claim the good back or if $d>l$, there is no contract.

c) If $d<l$, Owner offers Taker $l-d+\varepsilon$ in exchange for giving up the right to take, and Taker accepts.

\section{b) Behavioral Theory}

The predictions from standard theory are qualified by well-known behavioural effects, specifically by the possibility that either party may have a preference for fairness. Critically, there are different possible understandings of what is fair in this context.

Competing Fairness Norms. We begin with notions of fairness that are independent of our treatments - that do not depend on how the entitlement is protected. First, participants might desire equal outcomes, such that the fair contract price would be: $h / 2=l=24$. Second, participants might deem it appropriate to split in half the gains from avoiding an inefficient taking, such that the fair contract price would be: $(h-l) / 2=12$.

Other notions of fairness depend on how the entitlement is protected. For example, participants may consider outside options, as defined by the degree of protection. Or they may define a fair bargain as the cooperative Nash bargaining outcome (Nash 1950). The fair contract price would then be: $(h+l) / 2-d{ }^{6}$ Table 1 summarizes alternative definitions of fairness, as a function of the seven treatments.

$6 \quad$ Writing $o$ for the size of the offer, the result can be found by maximizing the following equation wrt $o$ : ( $h$ $o-d)(o-l+d)$. The first bracket is the original possessor's payoff if trade occurs, minus her outside option. The second bracket is the potential taker's payoff, minus her outside option. 


\begin{tabular}{|c|c|c|c|c|c|}
\hline Damages & $\begin{array}{l}\text { Owner's } \\
\text { Outside } \\
\text { Option }\end{array}$ & $\begin{array}{l}\text { Taker's } \\
\text { Outside } \\
\text { Option }\end{array}$ & $\begin{array}{l}\text { Nash } \\
\text { Bargaining }\end{array}$ & $\begin{array}{l}\text { Equal } \\
\text { Payoffs }\end{array}$ & $\begin{array}{l}\text { Equal Gains } \\
\text { from Avoiding Inefficient } \\
\text { Taking }\end{array}$ \\
\hline$d$ & $\begin{array}{c}d, \text { or } \\
\text { if } d>1: h\end{array}$ & $\begin{array}{l}1-d, \text { or } \\
\text { if } d>1: 0\end{array}$ & $(h+l) / 2-d$ & $h / 2$ & $(h-l) / 2$ \\
\hline 0 & 0 & 24 & 36 & 24 & 12 \\
\hline 6 & 6 & 18 & 30 & 24 & 12 \\
\hline 12 & 12 & 12 & 24 & 24 & 12 \\
\hline 18 & 18 & 6 & 18 & 24 & 12 \\
\hline 24 & 24 & 0 & 12 & 24 & 12 \\
\hline 30 & 48 & 0 & 6 & 24 & 12 \\
\hline back & (48) & (0) & (0) & 24 & 12 \\
\hline
\end{tabular}

Table 1: Alternative Notions of Fairness

Another notion of fairness, not included in Table 1, is the fairness norm of entitlement (on this fairness norm see Hoffman and Spitzer 1985, Kahneman, Knetsch et al. 1986): it is fair that those who had to work hard, or those that have otherwise been singled out as worthy recipients, end up with a larger share of the pie. In the experiment, owners have to work for the good in all treatments, but stronger protection may trigger a stronger sense of entitlement. This implies a positive correlation between WTP and the degree of protection afforded to the entitlement. This fairness norm may also be related to the endowment effect. ${ }^{7}$ Moreover, since the design of the experiment empowers Owner to make a take it or leave it offer, she might feel entitled to receive a higher payoff. The original possessor may also consider it normatively desirable that she keep the good because this is the efficient outcome (on the efficiency motive as a determinant of behaviour see Charness and Haruvy 2002, Engelmann and Strobel 2004). Yet takers may also be motivated by the fairness norm of entitlement.

See Lewinsohn-Zamir (2001). The endowment effect has been tested in the experiment that is closest to ours (Rachlinski and Jourden 1998). They ask participants to indicate a hypothetical choice in one of two vignettes. The first vignette describes a conflict between neighbors, with the additional flavor of a conflict between environmental protection and profit. The second vignette describes a conflict over the supply of a rare plant, and again introduces a conflict between environmental protection and profit. The law either protects the participant or her opponent, and either uses a property right, high or low damages. The authors are interested in the endowment effect, as a function of the legal remedy. They find a pronounced gap between willingness to accept and willingness to pay if there is a property right, but not with low damages. With high damages, results differ between the two vignettes. Overall, and contrary to the Coase theorem, the good in question is very unlikely to trade. Trade is least likely when the owner enjoys property right protection. But this effect might at least partly be explained by the loaded environmental frame of both vignettes.

Our experiment is deliberately unframed. The good is a mere token. No endowment effect has been found with tokens (Kahneman, Knetsch et al. 1990). Attachment, which is one potential source of the endowment effect, is unlikely to form with tokens (cf. Kelman 1978, Brosnan, Jones et al. 2007). We also avoid talking about property, and simply define the remedy in case the second participant takes the good. This also makes it unlikely that we see an effect of what the behavioral literature calls the expressive function of law (McAdams 2000b, McAdams 2000a, McAdams and Nadler 2005, McAdams 2015). Regret, another potential source of the endowment effect, is also unlikely to be triggered, since the role of Owner is assigned by the experimenter (cf. Gilovich and Medvec 1995). By contrast, loss aversion may be a relevant concern, as the initial allocation of the good alters the reference point against which the first participant evaluates each state of the world (Kahneman, Knetsch et al. 1991, Tversky and Kahneman 1991, Thaler, Tversky et al. 1997, Köszegi and Rabin 2006). Arguably this effect is even more likely since Owner had to work for the good, while Taker just has the technical possibility to seize the good. This might create an imbalance in terms of equity (on this fairness norm see Charness and Haruvy 2002, Beckman, Formby et al. 2004, Balafoutas, Kocher et al. 2013). 
Since they are given the ability to take the good and since the bargaining protocol gives them the power to veto any offer, Takers might conclude that they are entitled to a large payment, the more so the smaller the compensation.

A final harm-based fairness norm bears emphasis. A higher degree of protection reduces the harm to Owner from a taking and makes a taking more acceptable. As a result, Taker demands a higher bribe to refrain from taking the entitlement (higher WTA); and Owner is willing to pay a higher bribe to prevent a taking (higher WTP). This fairness norm is consistent with Gneezy and Rustichini (2000), where a higher fine (which is equivalent to higher compensation) increased the subjects' willingness to violate the rule.

The different fairness norms can be divided into three groups: (1) fairness norms that imply a negative relationship between the remedy and WTP/WTA (hereinafter: "negative fairness norms"), (2) fairness norms that imply a positive relationship between the remedy and WTP/WTA (hereinafter: "positive fairness norms"), and (3) fairness norms that imply a zero correlation, or flat relationship, between the remedy and WTP/WTA (hereinafter: "flat fairness norms”).

The existence of different plausible fairness norms allows for a clash of norms that might prevent an efficient Coasean bargain (Konow 2000). "A party may ask for too much, misconceiving the other's true position” (Kaplow and Shavell 1996: 764). In our setup, the rich set of potential fairness norms makes it particularly difficult to predict the other party's willingness to pay or accept (Bar-Gill and Engel 2016). The problem is exacerbated by the self-serving bias (Loewenstein, Issacharoff et al. 1993, Babcock and Loewenstein 1997), which looms particularly large in ambiguous situations (Haisley and Weber 2010). Different, self-serving fairness interpretations by Owner and Taker might create an obstacle to efficient trade.

The different behavioral effects can be incorporated into the parties' utility functions as follows: Let $\pi$ denote Owner's offer. In the behavioral theory (or theories), this offer is compared to the fair offer as perceived by the parties. Let $\pi_{O}^{F}(d)$ denote the fair offer, as perceived by Owner, and let $\pi_{T}^{F}(d)$ denote the fair offer as perceived by Taker. As explained above, $\pi_{O}^{F}(d)$ and $\pi_{T}^{F}(d)$ can depend on the remedy, $d$. An Owner who offers $\pi$ incurs a "fairness cost" of $\sigma_{O} \cdot \max \left(\pi-\pi_{O}^{F}(d), 0\right)$, where $\sigma_{O}$ denotes the intensity of Owner's fairness preferences. (We assume that the fairness cost is incurred only if the offer is accepted.) A Taker who accepts an offer, $\pi$, incurs a "fairness cost" of $\sigma_{T} \cdot \max \left(\pi_{T}^{F}(d)-\pi, 0\right)$, where $\sigma_{T}$ denotes the intensity of Taker's fairness preferences. Note that the standard theory (from subsection a) is a special case of this formalization, where $\sigma_{O}=\sigma_{T}=0$. Focusing on the $d=0, \ldots, 30$ treatments, we can now state the parties utility functions. Owner's utility function is

$$
u_{O}=\left\{\begin{array}{cc}
d & \text { Taking } \\
h-\pi-\sigma_{O} \cdot \max \left(\pi-\pi_{O}^{F}(d), 0\right) & , \text { No Taking }
\end{array}\right.
$$


And Taker's utility function is

$$
u_{T}=\left\{\begin{array}{cc}
l-d & , \quad \text { Taking } \\
\pi-\sigma_{T} \cdot \max \left(\pi_{T}^{F}(d)-\pi, 0\right) & , \quad \text { No Taking }
\end{array}\right.
$$

Taker will take iff $l-d>\pi-\sigma_{T} \cdot \max \left(\pi_{T}^{F}(d)-\pi, 0\right)$. We focus on the $\pi \leq \pi_{T}^{F}(d)$ case. In this case, Taker's WTA is $\pi=\frac{l-d+\sigma_{T} \pi_{T}^{F}(d)}{1+\sigma_{T}}$. (If $\pi>\pi_{T}^{F}(d)$, we return to the standard model and WTA is $l-d$.) When the intensity of Taker's fairness preferences is low, WTA is decreasing in $d$. When the intensity of Taker's fairness preferences is high, WTA can be either decreasing or increasing in $d$. In particular, when $\frac{\partial \pi_{T}^{F}(d)}{\partial d} \leq 0$, WTA is decreasing in $d$; when $\frac{\partial \pi_{T}^{F}(d)}{\partial d}>0$, WTA is increasing in $d$ if $\sigma_{T}>1 / \frac{\partial \pi_{T}^{F}(d)}{\partial d}$. Owner who has all the bargaining pow$\partial d$
er will offer $\pi=\frac{l-d+\sigma_{T} \cdot \widehat{\pi}_{T}^{F}(d)}{1+\sigma_{T}}$, as long this offer satisfies: $h-\pi-\sigma_{O} \cdot \max \left(\pi-\pi_{O}^{F}(d), 0\right)>$ $d$. Importantly, Owner's offer is not a direct function of the fair offer, as perceived by Taker, $\pi_{T}^{F}(d)$; rather, Owner's offer is a function of Owner's beliefs about $\pi_{T}^{F}(d)$, which we denote by $\hat{\pi}_{T}^{F}(d)$. Indeed, thinking that her notions of fairness are universal, an imperfectly rational Owner might substitute $\hat{\pi}_{T}^{F}(d)=\pi_{O}^{F}(d)$. With slight abuse of terminology, we call Owner's offer, WTP. (For further discussion, see Section 4(b).) Like Taker's WTA, Owner's WTP can be either increasing or decreasing in $d$.

Predicted treatment effects. With property rule protection, i.e., if the remedy for taking is the enforceable right of Owner to get the good back, efficiency is not at risk. The efficient outcome cannot be thwarted by a clash of fairness norms. These behavioral effects may however be present in the remaining six treatments. (With compensation of 24 or 30, taking the good does not increase Taker's profit. But depending on the strength of her fairness concerns, she may nonetheless take. In anticipation, Owner may nonetheless make an offer.) We thus have (partly) competing hypotheses:

H2: a) In the property rule treatment, Owner keeps the good.

b) In the liability rule treatments, a significant fraction of Owners do not keep the good.

c1) In the liability rule treatments, willingness to pay and willingness to accept decrease in the amount of compensation.

c2) In the liability rule treatments, willingness to pay and willingness to accept increase in the amount of compensation

\section{Results}

\section{a) Descriptives}

Figure 1 summarizes descriptive statistics. Owners very often make an offer. In principle offers are more likely, when the entitlement is weakly protected (i.e., when damages for taking are lower). Except that when the Owner is not protected at all (i.e., when damages are zero), 
only 58\% of Owners make an offer. Interestingly, 55\% of Owners make an offer even when taking is pointless since the good is protected by a property rule. By the design of the experiment, Owners only indicate their willingness to pay (WTP) if they make an offer. Therefore, the WTP data is subject to selection. With this caveat in mind, we see that WTP is lower, when the Owner enjoys stronger protection.

Turning to Takers, generally a Taker's willingness to accept (WTA) is higher, when Owner is better protected. Except that Takers' WTA is also high when Owner is not protected at all. Quite a few Takers decide to take the good if the Owner's offer is below their willingness to accept. 52\% of Takers decide to take the good even when damages exceed their valuation (d30), and 37\% of Takers take the good if a property rule is in place. Overall, contracts are not frequent. When Owner enjoys stronger protection, a contract is less likely.
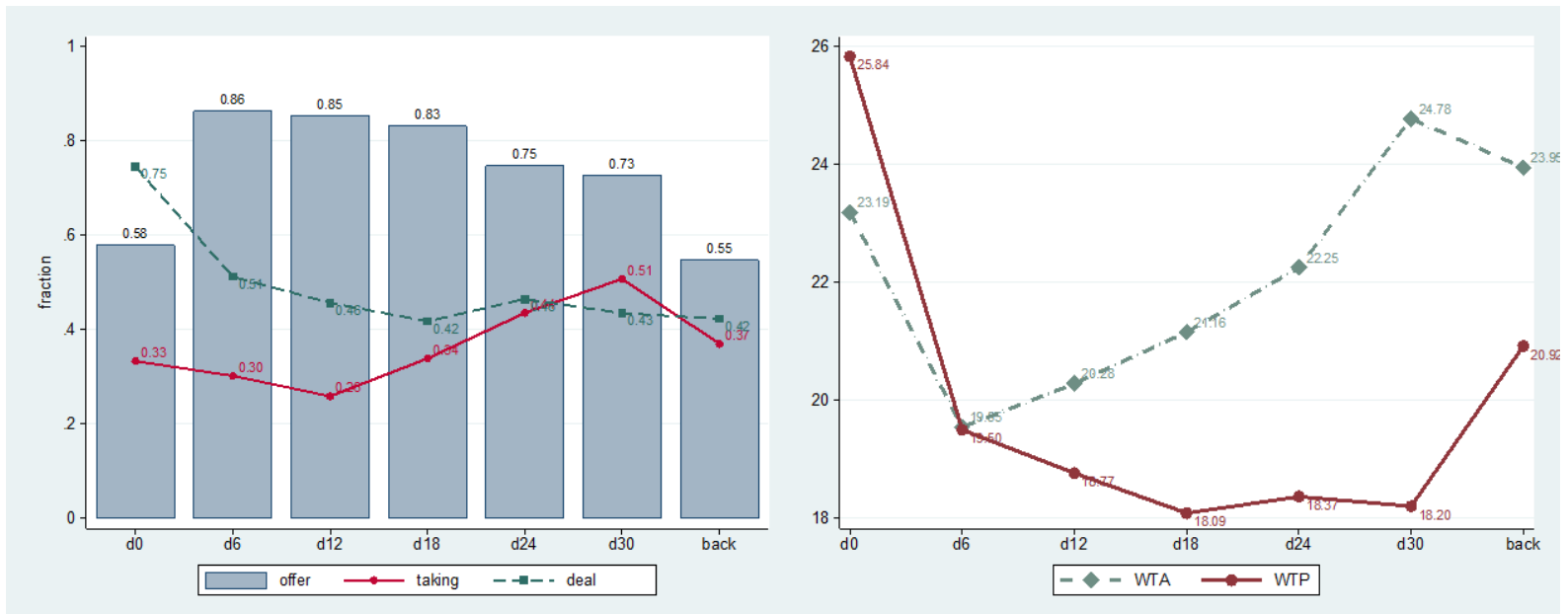

Figure 1: Descriptive Statistics

deal: probability of a deal provided Owner has made an offer taking: percentage of Takers who take if there is no deal

\section{b) Standard Theory}

Our results are, at best, only partially consistent with standard theory as summarized in H1. See Table 2 below. In most cases, the standard theory predictions for both WTA and WTP fall outside the empirical 95\% confidence interval generated by our data. In the property rule and d30 regimes, standard theory predicts no bargain. Yet, we obtain positive WTAs and WTPs. In the lower damages regimes, standard theory predicts that Taker's WTA will be $l-d+\varepsilon$. (Table 2 sets $\varepsilon$ at the smallest positive increment available to participants, i.e. 1.) According to standard theory, the maximum amount that Owner would be willing to pay is $h-d+\varepsilon$, based on Owner's outside option (and independent of the parties' relative bargaining power). But since Owner has all the bargaining power, standard theory predicts that Owner will offer $l-d$ $+\varepsilon$, and we call this offer WTP. Indeed, we believe that the instructions (provided in the Appendix), when asking for Owner's WTP, would reasonably be understood as asking how 
much Owner would offer, given that Owner has all the bargaining power. In any event, standard theory predicts an inverse relationship between the degree of protection (specifically, the level of damages) and both WTA and WTP. While we observe such an inverse relationship for WTP (excluding the property rule regime), on average WTA is actually increasing in the degree of protection (excluding the zero damages regime).

\begin{tabular}{|c|c|c|c|c|c|c|}
\hline & \multicolumn{3}{|c|}{ Taker's WTA } & \multicolumn{3}{|c|}{ Owner's WTP } \\
\hline & \multirow{2}{*}{$\begin{array}{l}\text { Standard } \\
\text { Theory }\end{array}$} & \multicolumn{2}{|c|}{ Data } & \multirow{2}{*}{$\begin{array}{l}\text { Standard } \\
\text { Theory }\end{array}$} & \multicolumn{2}{|c|}{ Data } \\
\hline & & $\begin{array}{c}\text { Point } \\
\text { Estimate }\end{array}$ & $\begin{array}{l}\text { Confidence } \\
\text { Interval }\end{array}$ & & $\begin{array}{c}\text { Point } \\
\text { Estimate }\end{array}$ & $\begin{array}{l}\text { Confidence } \\
\text { Interval }\end{array}$ \\
\hline $\mathrm{d} 0$ & 25 & 23.19 & {$[18,26]$} & 25 & 25.84 & {$[25,27]$} \\
\hline d6 & 19 & 19.55 & {$[16,21]$} & 19 & 19.50 & {$[16,21]$} \\
\hline $\mathrm{d} 12$ & 13 & 20.28 & {$[17,21]$} & 13 & 18.77 & {$[15,19]$} \\
\hline $\mathrm{d} 18$ & 7 & 21.16 & {$[17,22]$} & 7 & 18.09 & {$[15,18]$} \\
\hline $\mathrm{d} 24$ & 0 & 22.25 & {$[19,24]$} & 0 & 18.37 & {$[14,19]$} \\
\hline$d 30$ & 0 & 24.78 & {$[21,27]$} & 0 & 18.20 & {$[14,19]$} \\
\hline back & 0 & 23.95 & {$[21,26]$} & 0 & 20.92 & {$[15,24]$} \\
\hline
\end{tabular}

Table 2: Testing the Predictions of the Standard Theory - WTP and WTA

confidence intervals are from a series of one sample ranksum tests against the null hypothesis that WTP or WTA is $\mathrm{x}$ intervals report the lowest and the highest $x$ that is not rejected at the $5 \%$ level

The probability that Owner makes an offer and the probability that a deal is struck are also inconsistent with standard theory. Again, we expect no offer and thus no deal when Taker has no credible threat to take; yet we see a substantial number of offers and deals in these scenarios. When Taker has a credible threat, standard theory predicts a $100 \%$ probability of both offers and deals. We see a large, though not $100 \%$, probability of offers, but a much lower probability of deals. See Table 3.

\begin{tabular}{|c|c|c|c|c|c|c|}
\hline & \multicolumn{3}{|c|}{$\begin{array}{c}\text { Probability that Owner Makes an } \\
\text { Offer }\end{array}$} & \multicolumn{3}{|c|}{$\begin{array}{c}\text { Probability of a Deal } \\
\text { if Owner has Made an Offer }\end{array}$} \\
\hline & \multirow{2}{*}{$\begin{array}{l}\text { Standard } \\
\text { Theory }\end{array}$} & \multicolumn{2}{|c|}{ Data } & \multirow{2}{*}{$\begin{array}{l}\text { Standard } \\
\text { Theory }\end{array}$} & \multicolumn{2}{|c|}{ Data } \\
\hline & & $\begin{array}{c}\text { Point } \\
\text { Estimate }\end{array}$ & $\begin{array}{l}\text { Confidence } \\
\text { Interval }\end{array}$ & & $\begin{array}{c}\text { Point } \\
\text { Estimate }\end{array}$ & $\begin{array}{l}\text { Confidence } \\
\text { Interval }\end{array}$ \\
\hline d0 & 1 & 0.58 & {$[.45, .75]$} & 1 & 0.75 & {$[.65, .8]$} \\
\hline d6 & 1 & 0.86 & {$[.75, .95]$} & 1 & 0.51 & {$[.45, .6]$} \\
\hline $\mathrm{d} 12$ & 1 & 0.85 & {$[.75, .95]$} & 1 & 0.46 & {$[.4, .55]$} \\
\hline $\mathrm{d} 18$ & 1 & 0.83 & {$[.7, .9]$} & 1 & 0.42 & {$[.35, .5]$} \\
\hline $\mathrm{d} 24$ & 0 & 0.75 & {$[.6, .85]$} & $\mathrm{N} / \mathrm{A}$ & 0.46 & {$[.4, .55]$} \\
\hline $\mathrm{d} 30$ & 0 & 0.73 & {$[.6, .85]$} & $\mathrm{N} / \mathrm{A}$ & 0.43 & {$[.35, .55]$} \\
\hline back & 0 & 0.55 & {$[.4, .7]$} & $\mathrm{N} / \mathrm{A}$ & 0.42 & {$[.3, .55]$} \\
\hline
\end{tabular}

Table 3: Testing the Predictions of Standard Theory - Probability of Offer and Deal confidence intervals are from a series of binomial tests against the null hypothesis that WTP or WTA is $x$ intervals report the lowest and the highest $x$ that is not rejected at the $5 \%$ level

Turning to efficiency, standard theory predicts $100 \%$ efficiency. While we don't get $100 \%$ efficiency, the probability of efficient outcomes is relatively high across treatments. This rather high degree of efficiency is however not attributed to successful Coasean bargaining. (Recall that the probability of a deal is relatively low across treatments). Rather, the higher 
degree of efficiency results from the fact that Takers are reluctant to take when Owner's offer is below their WTA, Table 4.

\begin{tabular}{|c|c|c|c|c|c|c|}
\hline & \multicolumn{3}{|c|}{ Probability of Efficient Outcome } & \multicolumn{3}{|c|}{$\begin{array}{l}\text { Probability of Taking } \\
\text { when WTP }<\text { WTA }\end{array}$} \\
\hline & \multirow{2}{*}{$\begin{array}{l}\text { Standard } \\
\text { Theory }\end{array}$} & \multicolumn{2}{|c|}{ Data } & \multirow{2}{*}{$\begin{array}{l}\text { Standard } \\
\text { Theory }^{8}\end{array}$} & \multicolumn{2}{|c|}{ Data } \\
\hline & & $\begin{array}{c}\text { Point } \\
\text { Estimate }\end{array}$ & $\begin{array}{c}\text { Confidence } \\
\text { Interval }\end{array}$ & & $\begin{array}{c}\text { Point } \\
\text { Estimate }\end{array}$ & $\begin{array}{c}\text { Confidence } \\
\text { Interval }\end{array}$ \\
\hline d0 & 1 & 0.81 & {$[.75, .85]$} & N/A & 0.34 & {$[.25, .45]$} \\
\hline $\mathrm{d} 6$ & 1 & 0.83 & {$[.75, .9]$} & $\mathrm{N} / \mathrm{A}$ & 0.33 & {$[.25, .45]$} \\
\hline d12 & 1 & 0.84 & {$[.8, .9]$} & N/A & 0.34 & {$[.25, .45]$} \\
\hline d18 & 1 & 0.78 & {$[.7, .8]$} & $\mathrm{N} / \mathrm{A}$ & 0.36 & {$[.3, .5]$} \\
\hline$d 24$ & 1 & 0.72 & {$[.65, .7]$} & N/A & 0.40 & {$[.35, .55]$} \\
\hline d30 & 1 & 0.65 & {$[.6, .7]$} & N/A & 0.52 & {$[.45, .65]$} \\
\hline back & 1 & 1 & 1 (by design) & $\mathrm{N} / \mathrm{A}$ & 0.37 & {$[.3, .45]$} \\
\hline
\end{tabular}

Table 4: Testing the Predictions of Standard Theory - Probability of Efficient Outcome and of Taking

confidence intervals are from a series of binomial tests against the null hypothesis that WTP or WTA is $x$ intervals report the lowest and the highest $x$ that is not rejected at the $5 \%$ level

\section{c) Behavioral Theory}

We thus largely reject the predictions from standard theory and turn to the behavioral alternative. Less than $100 \%$ efficiency is very common in bargaining experiments. Indeed, the overall percentage of efficient outcomes in our study, 76.39\%, is very much in line with the percentage of efficient outcomes obtained in other bargaining experiments (see, e.g., the metastudy by Prante, Thacher et al. (2007) which found that $69 \%$ of outcomes were efficient). That WTP and WTA measures differ from standard game-theoretic predictions is also very common in the literature, with the difference attributed to fairness norms (Babcock, Loewenstein et al. 1995, Babcock and Loewenstein 1997, Falk, Fehr et al. 2003, BerebyMeyer and Niederle 2005).

The most interesting finding, in our study, has to do with the relationship between the remedy for a taking, which represents the strength of the legal protection that Owner enjoys, and the WTP and WTA measures. As explained in Section 3(b), this relationship depends on the relative importance of different fairness norms. In particular, we have seen that there are three groups of fairness norms: (1) negative fairness norms that imply a negative relationship between the remedy and WTP/WTA, (2) positive fairness norms that imply a positive relationship between the remedy and WTP/WTA, and (3) flat fairness norms that imply a zero correlation, or flat relationship, between the remedy and WTP/WTA. Which of these (groups of) fairness norms dominates?

8 Under standard theory, WTP and WTA are irrelevant in treatments back and d30. In all other treatments, WTP is always larger than or equal to WTA (see discussion at the beginning of Section 4.b). 
Looking at Figure 1, overall we see a negative relationship between the remedy and WTP, but a positive relationship between the remedy and WTA. As the regressions in Table 5 show, these visual impressions are supported by statistical analysis. ${ }^{9}$

\begin{tabular}{|l|l|l|}
\hline & WTP & WTA \\
\hline remedy & $-.504^{\star}$ & $.525^{\star \star}$ \\
& $(.198)$ & $(.197)$ \\
\hline cons & $22.036^{\star \star \star}$ & $20.065^{\star \star \star}$ \\
& $(1.354)$ & $(.882)$ \\
\hline $\mathrm{N}$ & 489 & 665 \\
\hline
\end{tabular}

Table 5: Relationship between Damages and WTP/WTA

linear regressions with individual random effects, Hausman test insignificant on both models

WTP only available for owners who decide to make an offer WTP: willingness to pay of owner

WTA: willingness to accept of potential taker

remedy: $1 \mathrm{~d} 0,2 \mathrm{~d} 6,3 \mathrm{~d} 12,4 \mathrm{~d} 18,5 \mathrm{~d} 24,6 \mathrm{~d} 30,7$ back

standard errors in parentheses

${ }^{\star * *} p<.001,{ }^{* *} p<.01,{ }^{*} p<.05$

Seemingly fairness norms are role-dependent. Overall, Owners predominantly subscribe to negative fairness norms, whereas most Takers subscribe to positive fairness norms. Yet as the following analysis shows, averages obscure that, in both roles, we find substantial fractions of participants who can be classified as adhering to either positive, flat or negative fairness norms. In statistical jargon, we find heterogeneous treatment effects.

For classifying fairness types, we focus on the d6, d12, d18, d24 and d30 treatments, and use the slope of the parties' WTA or WTP choices across these treatments to classify each party as a positive type, a flat type or a negative type. ${ }^{10}$ In the appendix, we show that this measure organizes the data very well. Within each type, there is considerable variance regarding the level of WTA or WTP, but fairly little variance regarding the slope. ${ }^{11}$

Figure 2 depicts Owner's WTP as a function of the remedy, separately for each of the three types. It also reports beliefs. For positive and negative types, beliefs and choices match very well. For flat types, beliefs and choices have the same flat tendency, but not the same size. The match between beliefs and choices makes us confident that types are not spurious, and that positive types do not simply result from confusion, but rather represent participants who interpret a strong position of Owner as a justification for taking.

$9 \quad$ Controlling for gender and age does not substantially change results. These demographic variables do not themselves explain choices. The additional regression is available from the authors upon request.

10 Specifically, for each individual we regress WTA / WTP on remedy. We use the sign of this coefficient for classification. As Figure 2 and Figure 3 show, choices for the d0 and back regimes are less consistent. If we include them in the local regressions, our classification becomes more noisy.

11 The classification of each participant is available from the authors upon request. 


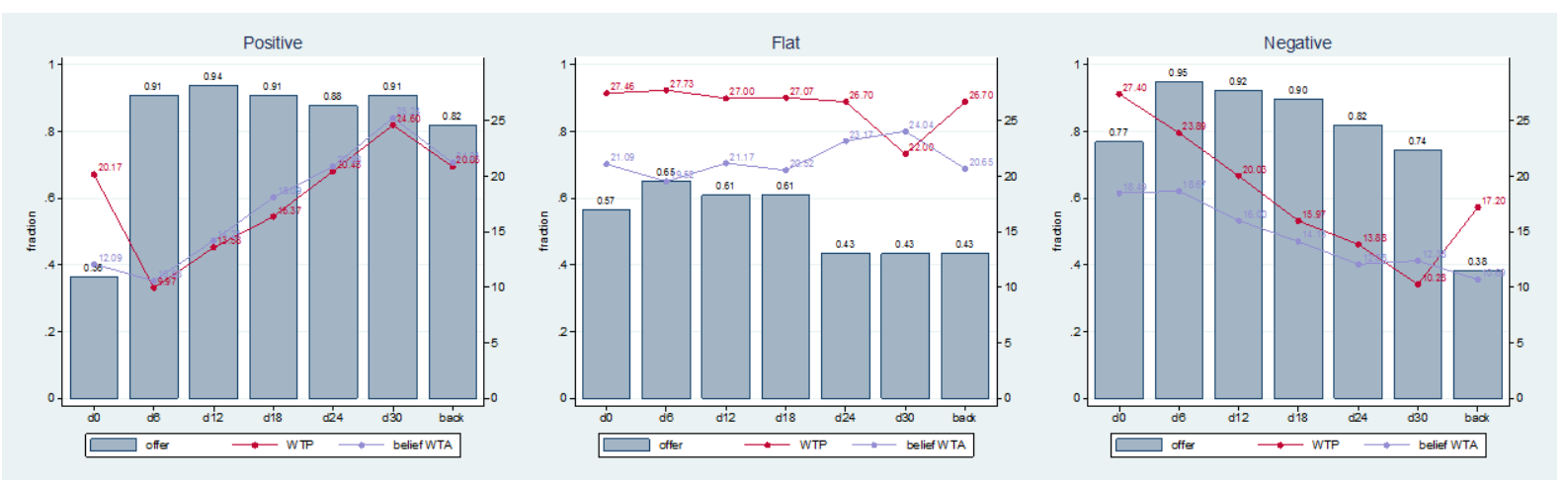

Figure 2: Three Distinct Types of Owners

Similarly, Figure 3 depicts Taker's WTA as a function of the remedy separately for each of the three groups. We again find the same three types, and we again find a good match between choices and beliefs. This gives us further confidence that all three types reflect different, characteristic interpretations and normative assessments of the situation, in the light of competing fairness norms.

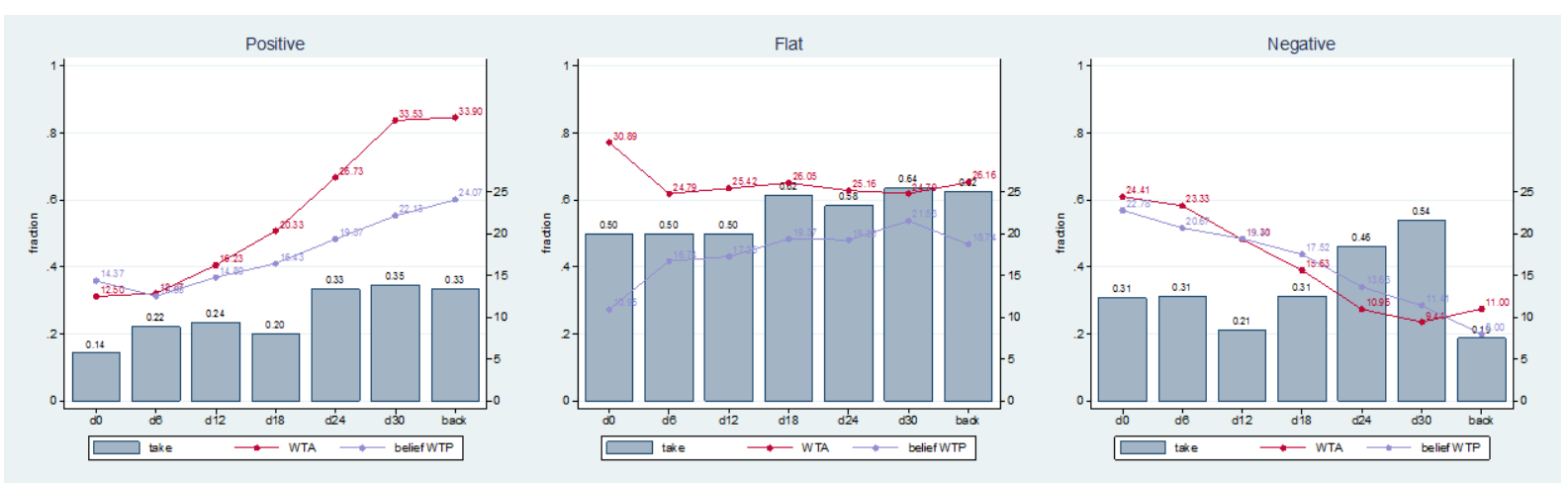

Figure 3: Three Distinct Types of Takers

take: probability that Taker takes if there is no deal 
The regressions show that the relationship between beliefs and choices is indeed systematic both for WTA and WTP: ${ }^{12}$

\begin{tabular}{|l|l|l|}
\hline & WTP & WTA \\
\hline belief & $.453^{\star \star \star}$ & $.359^{\star \star \star}$ \\
& $(.036)$ & $(.039)$ \\
\hline cons & $11.948^{\star \star \star}$ & $15.837^{\star \star \star}$ \\
& $(1.235)$ & $(1.339)$ \\
\hline $\mathrm{N}$ & 489 & 665 \\
\hline
\end{tabular}

Table 6: Relationship between Damages and WTP/WTA

linear regressions with individual random effects, Hausman test insignificant on both models WTP only available for owners who decide to make an offer WTP: willingness to pay of owner WTA: willingness to accept of potential taker standard errors in parentheses *** $p<.001,{ }^{* *} p<.01,{ }^{*} p<.05$

Finally, we compare the relative size of the three groups for subjects that were (randomly) assigned the role of Owner as compared to subjects that were (randomly) assigned the role of Taker. This comparison is depicted in Figure 4 below.

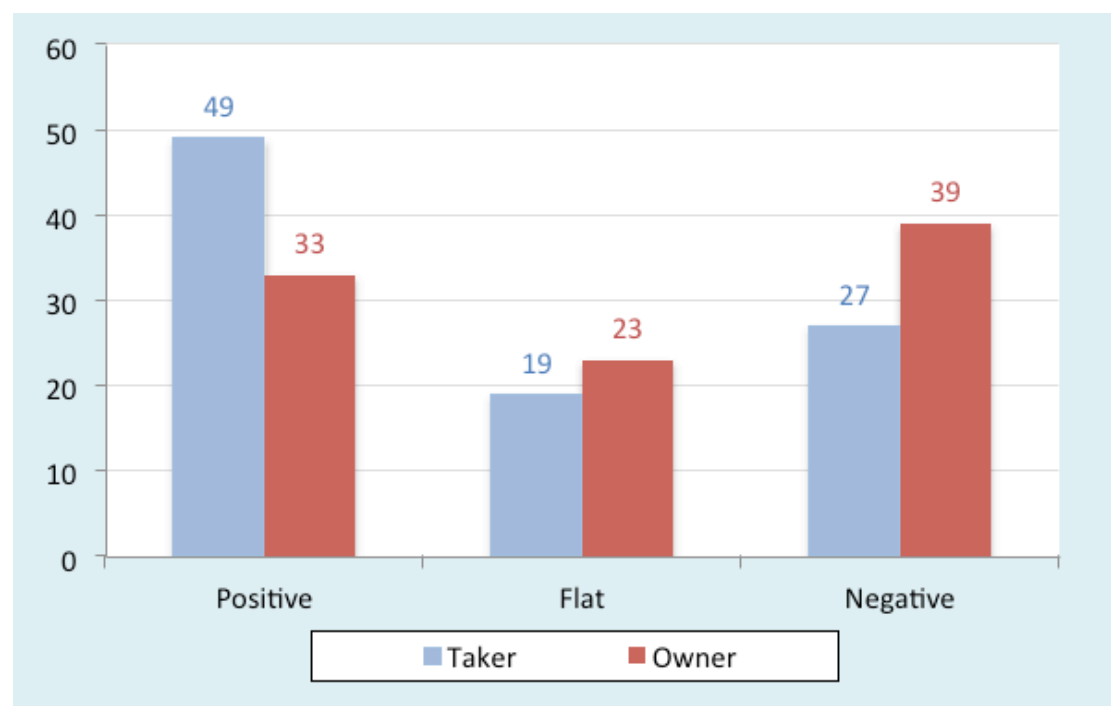

Figure 4: Role Dependent Types

We see that, indeed, Owners are more likely to subscribe to negative fairness norms, whereas Takers are more likely to subscribe to positive fairness norms. This relationship is systematic, (chi square $(1)=5.1995, \mathrm{p}=.023)$. Such role-dependent beliefs can be attributed to a selfserving bias. For Owner, stronger remedies readily translate to a lower willingness to pay (as predicted by standard theory). For Taker things are different: Recall that Owner has to earn the good in a laborious task. If Taker takes the good, she violates the fairness norms of enti-

12 Note that, with our design, we cannot decide whether participants first elaborated beliefs, and then chose accordingly, or whether they later stated beliefs such that they are consistent with their choices (for instance in the interest of preserving self-esteem). Defining this arrow of causality is, however, also not critical for our purposes. 
tlement (Owner loses the good) and of desert (the assignment of the good reflects a difference in effort). This makes it difficult for Takers with sensitivity towards fairness to take the good. This hesitance is reflected in the fairly low take rate (Figure 1). If Taker holds positive fairness preferences, she has access to an excuse: if she takes the good and compensation is high, she does not completely deprive Owner of what she deserves. She makes outcomes more equal without grossly violating due respect for entitlement and desert. It is therefore not surprising that more Takers, and fewer Owners, subscribe to this particular fairness norm. ${ }^{13}$

As Figure 2 and Figure 3 show, all participants try to match their WTA/WTP choices with their beliefs about their bargaining partners' WTP/WTA choices. Still, there are relatively few successful deals. Why? The reason is simply that a party's beliefs about her partner's WTP/WTA choices are often wrong. Importantly, a party might hold mistaken beliefs about her partner's WTP/WTA choices, while correctly estimating the partner's type. Indeed, a party who correctly believes that she and her partner are of the same type can even be less likely to strike a deal with that partner. Consider a positive-type Owner and a strong remedy (d30). This Owner will have a high WTP. If Taker is also of positive type, then Taker will have a high WTA; and possibly this WTA will exceed Owner's WTP, resulting in failed negotiations. In contrast, if Taker is of negative type or flat type, then Taker will have a lower WTA and the probability of a successful deal increases. Similarly, consider a negative-type Owner and a weak remedy (d6). This Owner will have a high WTP. If Taker is also of negative type, then Taker will have a high WTA; and possibly this WTA will exceed Owner's WTP, resulting in failed negotiations. In contrast, if Taker is of positive type or flat type, then Taker will have a lower WTA and the probability of a successful deal increases.

\section{Robustness and Extensions}

\section{a) Motivation for Supplementary Treatments}

Every experiment is the starting point for the next step in a process of investigation. In this spirit, we supplement the main experiment with a series of additional treatments. This additional exercise serves multiple purposes. We first want to see whether the type space replicates, and is robust to different specifications. This allows us to assess whether the normative problem generalizes. Second, ultimately the weakness of Coasean bargaining results from the fact that individuals hold incorrect beliefs about the type space. We explore whether it is possible to manipulate beliefs and thus increase the prevalence of efficient trade. Third, one of the findings from the main experiment may seem particularly surprising. On average, Takers are most likely to take the good if this costs them 30 ECU in damages. As the experimenter

13 We administered a series of post-experimental tests: for social value orientation, for risk aversion, for ambiguity aversion, and for the personality characteristics of the Big5 inventory. None of them explains why certain participants subscribe to certain fairness norms. This suggests that we see a type of fairness norm(s) that is not captured by any of these standard measures, specifically, the notion that taking is more permissible when Owner is more strongly protected. 
only redeems the good with 24 ECU if it is in the possession of Takers, with this remedy taking hurts both individuals: Owners and Takers. This result might suggest that many participants did not understand the instructions, and thus replication of this result is particularly important. If the finding is robust, it bears explanation. We replicate the result and identify the behavioral effect that explains it, thus alleviating concerns about possible misunderstanding.

\section{b) Design}

The supplementary treatments are extensions of the main experiment. In the main experiment, Owner must correctly count the number of $1 \mathrm{~s}$ in 10 tables filled with $1 \mathrm{~s}$ and 0 s of size 10x10. In the additional Severity treatments, we use the strategy method (Selten 1967) and have Owner and Taker decide conditional on Owner having to solve 5, 10 or 15 tables. We make it possible to elicit choices conditional on the burden for Owner by shifting the earning stage to the end of the experiment. Moreover, in the main experiment, taking has no explicit cost. In the additional Expressive treatments, we again use the strategy method and oblige Taker to solve 0,1 or 5 tables if she exercises her option to take the good. In these treatments, the earning stage is also shifted to the end.

In the main experiment we found that choices and beliefs closely match. We turn this finding into a feature of the design of the additional treatments. Together with the instructions, we give participants selective graphical information about choices in the main experiment. We inform participants that this information is selective. ${ }^{14}$ One of us has used this method in another experiment, where it has proven effective (Engel, Kube et al. 2016). Depending on treatment, participants see information that suggests a positive, flat, or negative fairness norm. These manipulations give us the 18 additional conditions listed in Table 7.

\begin{tabular}{|c|c|c|c|c|}
\hline \multirow{4}{*}{$\begin{array}{c}\text { within } \\
\text { subjects }\end{array}$} & \multicolumn{3}{|c|}{$\begin{array}{c}\text { between subjects } \\
\text { induced belief }\end{array}$} \\
\cline { 2 - 5 } & 5 & positive & flat & negative \\
\hline \multirow{3}{*}{ Severity } & 10 & SP10 & SF5 & SN5 \\
\cline { 2 - 5 } & 15 & SP15 & SF15 & SN10 \\
\hline \multirow{3}{*}{ Expressive } & 0 & EP0 & EF0 & EN0 \\
\cline { 2 - 5 } & 1 & EP1 & EF1 & EN1 \\
\cline { 2 - 5 } & 5 & EP5 & EF5 & EN5 \\
\hline
\end{tabular}

Table 7

Supplementary Treatments

The supplementary treatments were run in the same lab as the main experiment, using the same software (Fischbacher 2007, Bock, Baetge et al. 2014) and an adapted version of the original computer program. 174 subjects (who had not been involved in the main experiment) participated, 26 in the EF (Expressive-Flat), 28 in the SN (Severity-Negative), and 30 in each 
of the remaining four treatments. ${ }^{15} 105$ of them (60.34\%) were female. Mean age was 25.02 years. Participants on average earned $13.54 €$ (12.74€ for Takers, and 14.33€ for Owners).

\section{c) Robustness of the Type Space}

As Figure 5 and Figure 6 demonstrate, overall the main experiment replicates very well. We still find the same three types of Owners and Takers. Within each type, subjects' beliefs about the choices made by their counterparts match closely with the subject's own choices. ${ }^{16}$

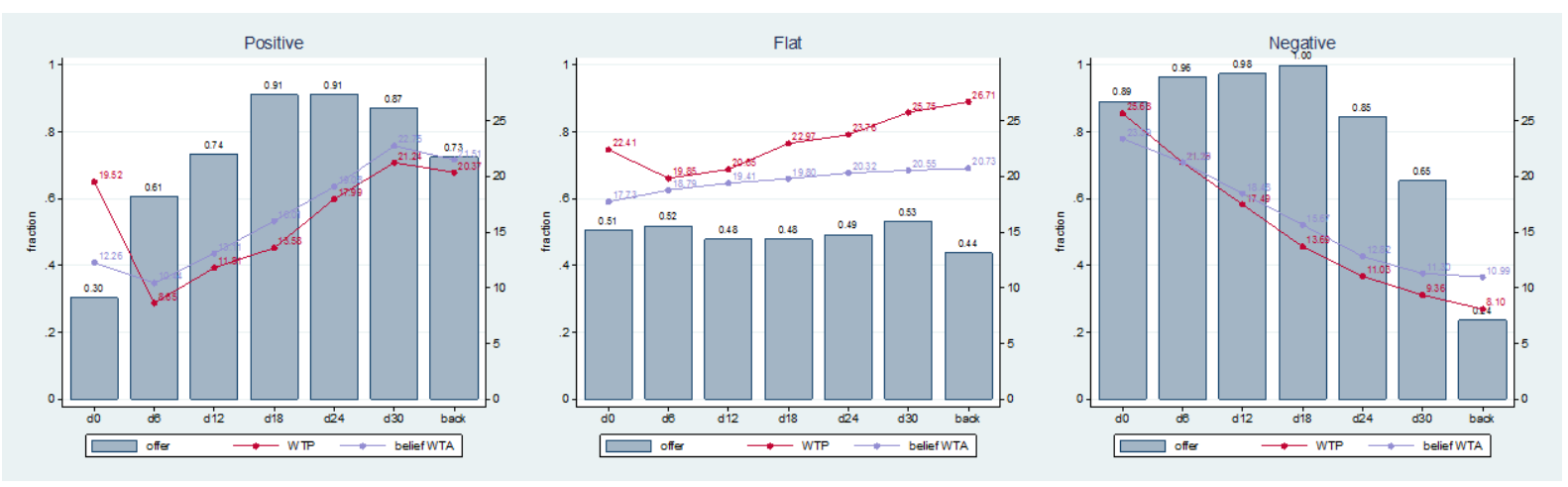

Figure 5

Types of Owners in Supplementary Treatments

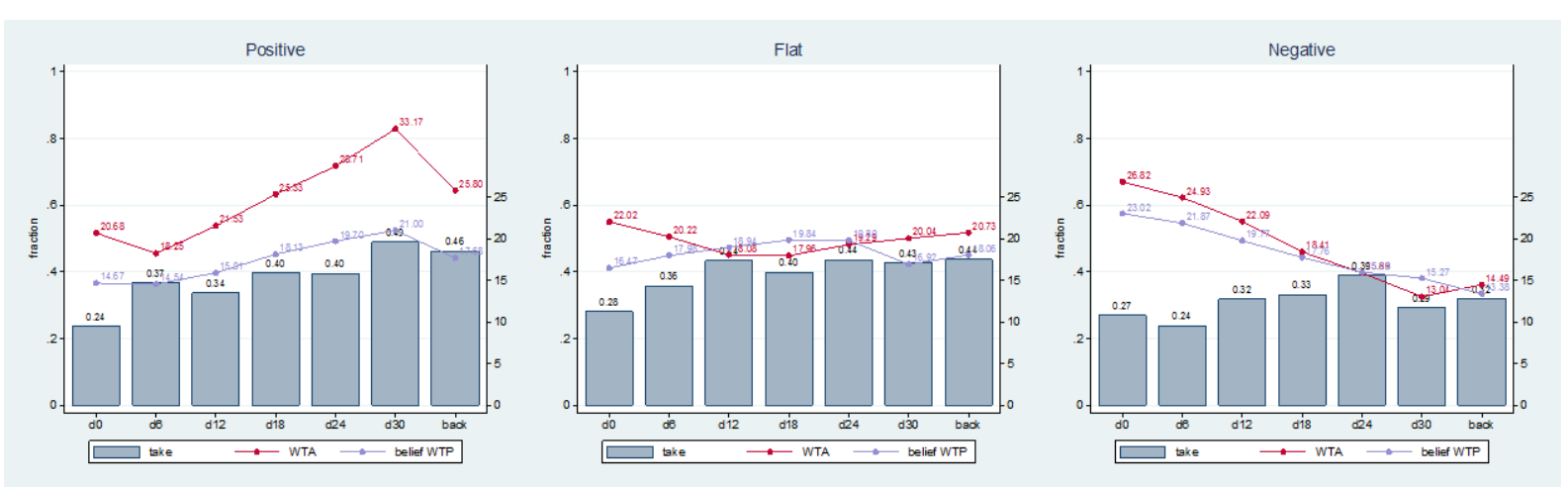

Figure 6

Types of Takers in Supplementary Treatments

15 In the EF and SN treatments, too many invited participants did not show up to fill the sessions. Note that Severity and Expressive, as well as the induced positive, flat or negative beliefs, are between subjects manipulations, while the amount of tables Owner (in the Severity treatments) or Taker (in the Expressive treatments) has to solve are within subjects manipulations.

16 See Figure 11, Figure 12, Figure 13, Figure 14 in the Appendix for offers and beliefs per condition and type. 


\section{d) Malleability of the Type Space}

We find only mild evidence for the malleability of the type space. Descriptively, there are more positive types if this type is induced, and more negative types if this type is induced. See Table 9. (Recall, we attempt to induce a type by showing subjects selective graphical information from the main experiment suggesting that subjects, in the main experiment, were of that type.) But the only difference that is significant at the $5 \%$ level is between positive and negative induced types of Takers (chi square, $\mathrm{p}=.031$ ). ${ }^{17}$

\begin{tabular}{|c|c|c|c|c|c|c|}
\hline \multirow{2}{*}{$\begin{array}{c}\text { empirical } \\
\text { type }\end{array}$} & \multicolumn{3}{|c|}{$\begin{array}{c}\text { induced type } \\
\text { takers }\end{array}$} & \multicolumn{3}{c|}{$\begin{array}{c}\text { induced type } \\
\text { owners }\end{array}$} \\
\cline { 2 - 7 } & positive & flat & negative & positive & flat & negative \\
\hline positive & 16 & 14 & 10 & 15 & 8 & 11 \\
\hline flat & 7 & 6 & 4 & 9 & 5 & 11 \\
\hline negative & 7 & 8 & 15 & 6 & 15 & 7 \\
\hline
\end{tabular}

Table 8

Type Space in Supplementary Treatments

\section{e) Irrational Takings?}

We now turn to the finding that taking occurs with high frequency in the d30 condition. Table 9 shows that this finding replicates. We observe some treatment variation. But overall the take rate is high with this remedy. And, for most conditions, taking when damages equal 30 is even more frequent than taking with the remaining remedies. What explains this finding?

\begin{tabular}{|c|c|c|c|c|}
\hline \multirow{5}{*}{ within } & \multicolumn{3}{|c|}{$\begin{array}{c}\text { between subjects } \\
\text { induced belief }\end{array}$} \\
\cline { 2 - 5 } & subjects & positive & flat & negative \\
\hline \multirow{5}{*}{ Severity } & 5 & $\begin{array}{c}47 \% \\
(47 \%)\end{array}$ & $\begin{array}{c}47 \% \\
(37 \%)\end{array}$ & $\begin{array}{c}71 \% \\
(30 \%)\end{array}$ \\
\cline { 2 - 5 } & 10 & $67 \%$ & $47 \%$ & $71 \%$ \\
& & $(50 \%)$ & $(36 \%)$ & $(33 \%)$ \\
\cline { 2 - 5 } & 15 & $80 \%$ & $40 \%$ & $71 \%$ \\
$(59 \%)$ & $(41 \%)$ & $(33 \%)$ \\
\hline \multirow{5}{*}{ Expressive } & 0 & $47 \%$ & $46 \%$ & $40 \%$ \\
& & $(32 \%)$ & $(42 \%)$ & $(28 \%)$ \\
\cline { 2 - 5 } & 1 & $33 \%$ & $38 \%$ & $20 \%$ \\
& & $(29 \%)$ & $(33 \%)$ & $(26 \%)$ \\
\cline { 2 - 5 } & 5 & $40 \%$ & $46 \%$ & $20 \%$ \\
$(29 \%)$ & $(26 \%)$ & $(21 \%)$ \\
\hline
\end{tabular}

Table 8

Percent of Taking in $\mathrm{d} 30$ Condition

(mean percent of taking with remaining 6 remedies in brackets)

17 We also find a weakly significant $(\mathrm{p}=.070)$ difference between flat and negative induced types of owners. 
Let us have a closer look at taking with the $\mathrm{d} 30$ remedy. The experimenter pays 24 if Taker is in possession of the good. If Taker has to compensate Owner with 30, taking costs her 6 . Owner only receives 30 , rather than redeeming the good for 48 with the experimenter. If Taker maximizes profit, she will not take under these circumstances. But Owner loses much more than Taker. At a cost of 6, Taker inflicts a harm of 18 on Owner. The literature on ultimatum games shows that many responders are willing to forego positive gains from trade if they consider the proposed split to be grossly unfair (Güth, Schmittberger et al. 1982, Slonim and Roth 1998, Abbink, Bolton et al. 2001, Cooper and Dutcher 2011). And the literature on public goods shows that many participants are willing to invest a considerable portion of their own income to punish free riders (Fehr and Gächter 2000, Fehr and Gächter 2002, Balliet, Mulder et al. 2011, Masclet, Noussair et al. 2013). Actually the "fine to fee ratio" in the d30 condition is $3: 1$, very much in line with the ratio frequently found in public good experiments (Nikiforakis and Normann 2008).

Yet in the $\mathrm{d} 24$ condition, "punishment" is free. And in the $\mathrm{d} 0$ - d18 conditions, taking pays a double dividend. Owner is punished, i.e., loses money, and Taker (the punisher) gains money. Why is it that, nonetheless, we find most taking in the $\mathrm{d} 30$ condition? Two behavioral effects could explain this finding. If Taker takes in the $\mathrm{d} 30$ condition, the selfish motive of increasing her own profit is ruled out. The meaning of the action is unequivocal: Taker wants to punish Owner. We may find most taking in the $\mathrm{d} 30$ condition because a fraction of takers cares about this expressive effect. Alternatively, taking behavior may be motivated by a severity effect: Takers might respect the hard work that Owners had to do to obtain the good. They might consider it illegitimate to take the good, if this leaves Owner with less than half (or, in the d24 condition exactly half) of her implicit wage. By contrast, in the d30 condition, compensation is $62.5 \%$ of Owner's maximum profit. Takers might consider a sanction of $37.5 \%$ of the maximum profit to be sufficiently proportionate to Owner's infraction, i.e. to offering an amount that Taker deems inappropriately low.

Our data do not support a significant expressive effect: We find no evidence that the high frequency of taking in the d30 treatment is motivated by the desire to unequivocally express dissatisfaction with Owner's offer. Looking at Figure 7, it seems that taking frequency actually goes down when Taker is herself obliged to exert laborious effort. Statistically we do not find a significant effect of the expressive manipulation on the frequency of taking. 


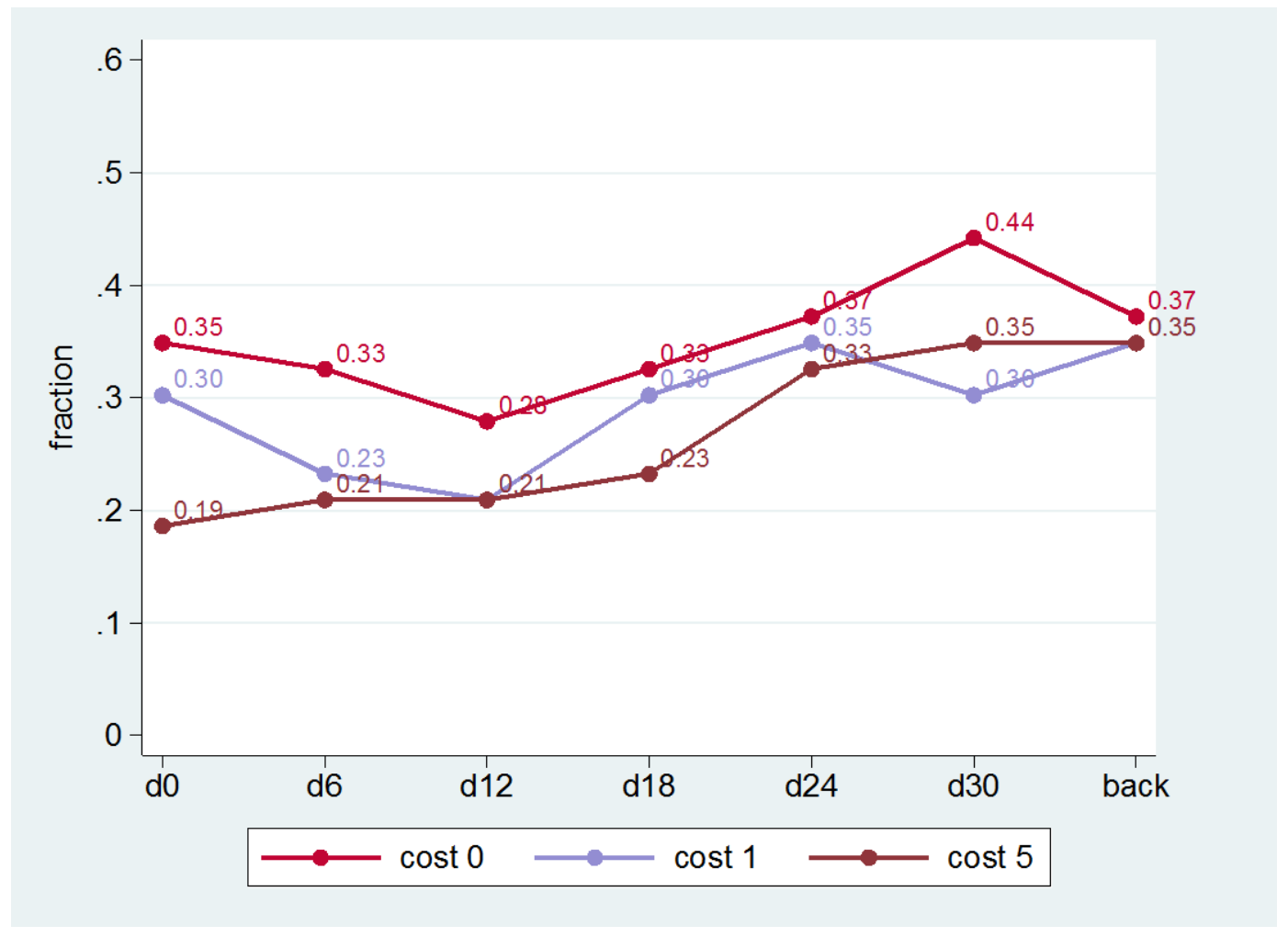

Figure 7

Frequency of Taking in the Expressive Treatments

In contrast, the data do support a significant severity effect. At first glance, the severity manipulation seems to have a perverse effect. From Figure 8, it appears that the good is most likely to be taken, when Owner has to work the hardest for the good. But this seemingly perverse effect is not statistically significant. Looking across the entire data, severity does not have a significant effect on taking frequency. 


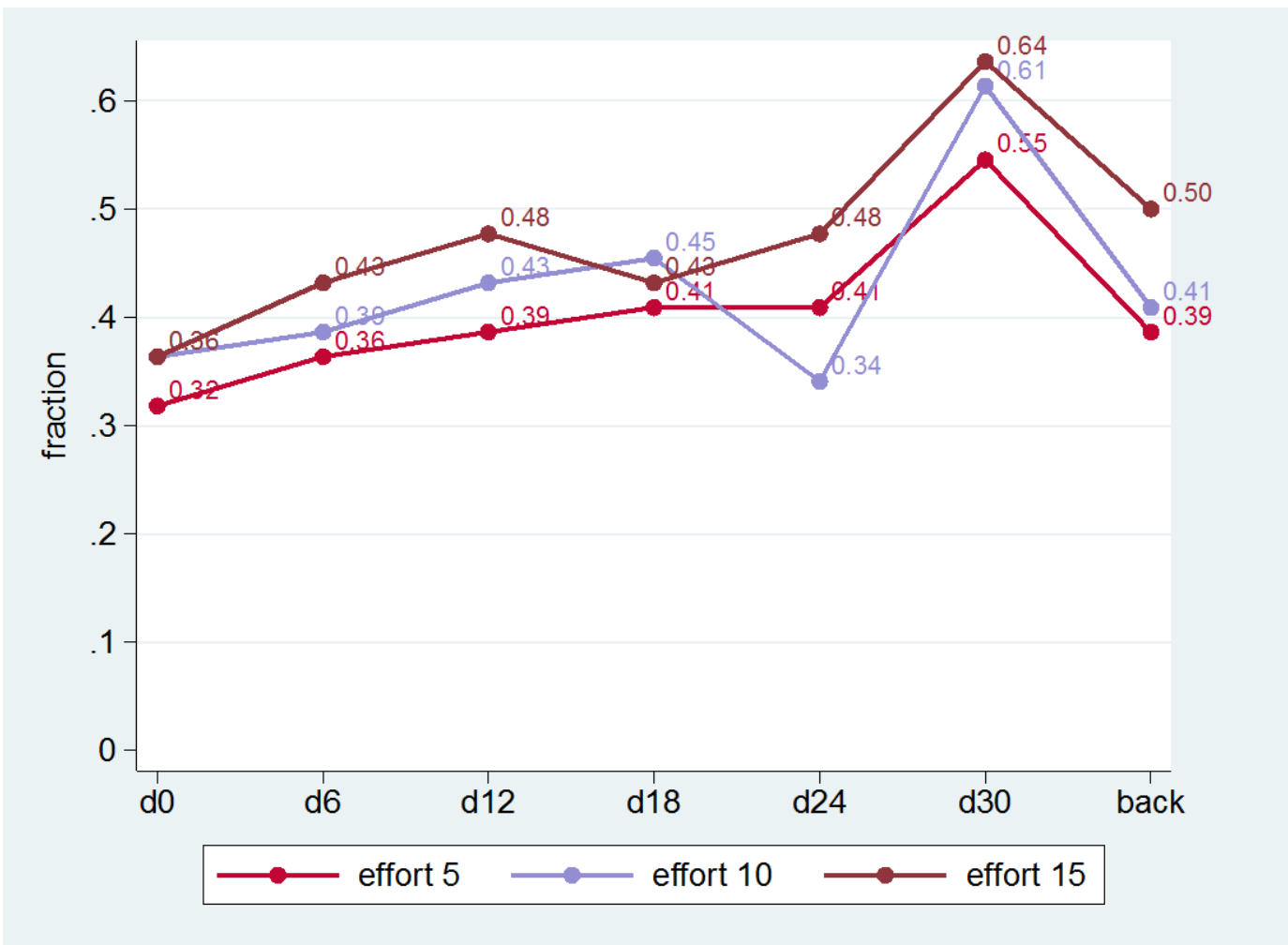

Figure 8

Frequency of Taking in the Severity Treatments

The effect of severity is revealed, when we parse the data and distinguish between two groups of takers - those who take the good if Owner offers less than their stated WTA (Takers-WhoTake) and those that do not take the good even if Owner offers less than their stated WTA (Takers-Who-Don't-Take). In the baseline model (Section 4), there is no pronounced difference between the WTA of Takers-Who-Take and Takers-Who-Don't-Take. ${ }^{18}$ By contrast, with the Severity manipulation, this difference is pronounced. Takers-Who-Don't-Take ask for much more (higher WTA), especially with remedies that disfavor Owner. For these individuals, the remedy plays little role, as they ultimately do not intend to take the good and incur the remedy. For Takers-Who-Take, on the other hand, WTA is significantly influenced by the remedy. They ask for more (higher WTA), when Owner is better protected, and most if the remedy is 30 ECU. For these individuals, the Severity manipulation makes the conflict with fairness of desert salient, as Owners and Takers have to choose conditional on the effort Owner must exert for owning the good. This is intuitive. In the Severity treatments, each participant decides for three different conditions: Owner has to solve 5, 10 or 15 tables to earn the good. This manipulation makes the link between taking laborious effort, and hence fairness of desert, salient.

18 With the exception of the d0 remedy: individuals who take the good with this remedy follow the logic of bargaining models. They understand that they have all the bargaining power. They ask for considerably more than their outside option of 24 ECU as Owner stands to loose much more, and take if Owner does not give them what they demand. 

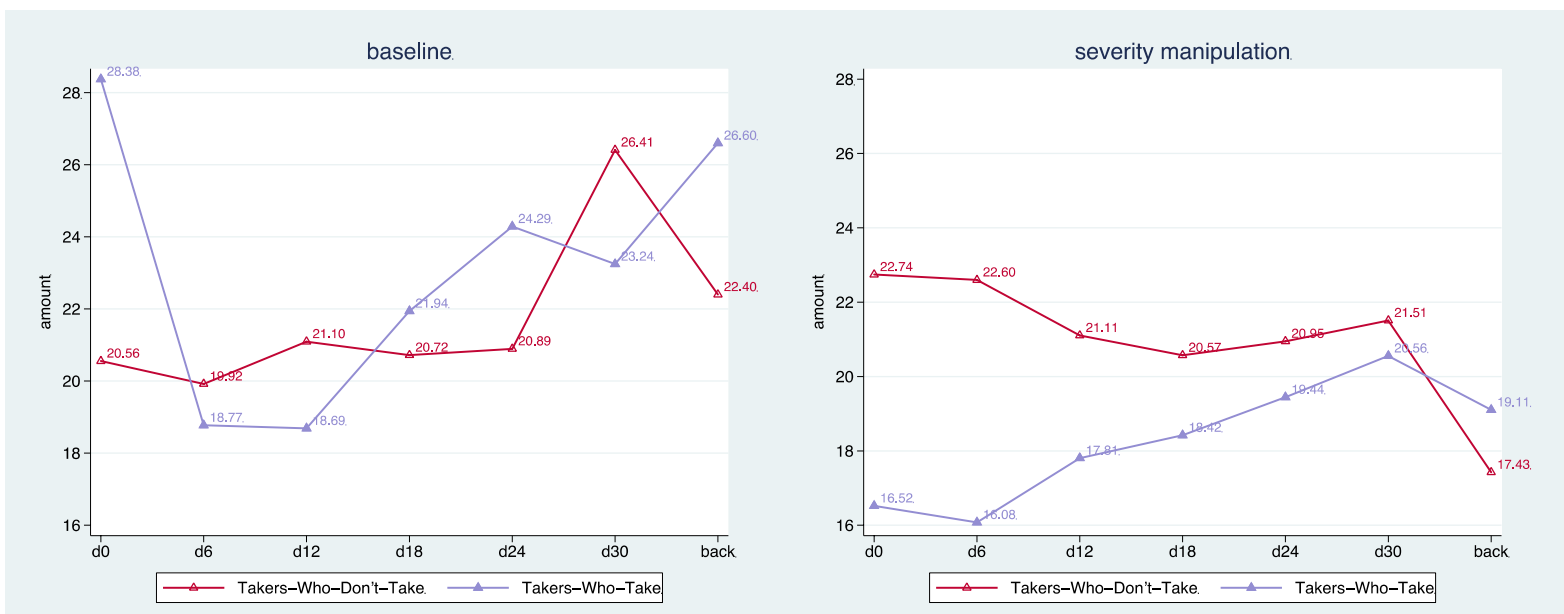

Figure 9

Willingness to Accept of Takers-Who-Take and Takers-

Who-Don't-Take

The visual impression is fully supported by statistical analysis. See Table 10. In the baseline model (the reference category), there is no significant difference between the WTA of TakersWho-Take and Takers-Who-Don't-Take (insignificant main effect of take). But there is sensitivity for the harm that taking imposes on Owner, as WTA increases in the degree with which Owner is protected - for both Takers-Who-Don't-Take (main effect of remedy) and TakersWho-Take (insignificant two-way interaction between take and remedy). In the severity treatments, this effect disappears for Takers-Who-Don't-Take (negative two-way interaction between severity and remedy). But Takers-Who-Take substantially increase their WTA, when Owner is better protected (three-way interaction). 


\begin{tabular}{|l|l|}
\hline severity & 3.220 \\
$(2.342)$ \\
\hline take & 1.110 \\
& $(1.884)$ \\
\hline severity * take & $-6.739^{\star \star}$ \\
& $(2.443)$ \\
\hline remedy & $.735^{\star \star}$ \\
& $(.222)$ \\
\hline severity * remedy & $-1.493^{\star \star \star}$ \\
& $(.296)$ \\
\hline take * remedy & -.514 \\
& $(.383)$ \\
\hline severity * take * remedy & $1.904^{\star \star \star}$ \\
& $(.497)$ \\
\hline cons & $19.621^{\star \star \star}$ \\
& $(1.471)$ \\
\hline $\mathrm{N}$ obs & 1589 \\
\hline $\mathrm{N}$ uid & 139 \\
\hline
\end{tabular}

Table 9

WTA of Takers-Who-Take and TakersWho-Don't-Take

linear model with individual random effects

standard errors in parenthesis

remedy: $1=\mathrm{d} 0 . .7=$ back

$* * * \mathrm{p}<.001, * * \mathrm{p}<.01, * \mathrm{p}<.05$

\section{f) Summary}

Supplementary treatments show that results from the main experiment are very robust. The type space replicates (a) if we manipulate the effort owner has to exert for earning the good, and thereby fairness of desert; (b) if we introduce a small cost of effort for taking; and (c) if we give participants selective information from the main experiment, and thereby aim at manipulating their beliefs about prevalent fairness norms. When taking is not profitable, as compensation is higher than the value that Taker stands to gain from the good, there is still a lot of taking. With most parameter values, taking is even most likely in this case. Apparently an important reason for taking is the intention to punish Owner for making an unacceptably low offer. We can rule out that this result is driven by an expressive effect - a desire to make the punishment motive unequivocal. Our data do however suggest respect for the effort Owner had to exert: when compensation is higher and Owner is better protected, this fairness concern plays a smaller role and Takers feel more free to demand more (higher WTA) and to take the good when their demands are not met. Exogenously influencing fairness perception does not seem to be a very promising strategy for harnessing the power of Coasean bargaining. 


\section{Conclusion}

In a complete information environment, standard theory predicts $100 \%$ efficiency, independent of remedy. Regardless of whether Owner enjoys strong protection or weak protection, the efficient outcome obtains. When Owner's entitlement is only weakly protected, she will need to pay Taker to prevent a taking. But the inefficient taking will not occur. This happy result does not survive the introduction of well-documented behavioral forces. Fairness concerns pull parties' WTP and WTA away from the predictions of standard theory, and away from each other. And when Taker's WTA exceeds Owner's WTP, Coasean bargaining cannot secure efficient outcomes. This is not surprising: Unobservable fairness concerns introduce information asymmetries, which are known to prevent efficient bargains.

Our experiment tested the effect of the legal remedy - how strong Owner's entitlement is protected - on the parties' fairness assessments, on their WTP and WTA, and on the likelihood of an efficient outcome. We identified three distinct types: (1) positive types whose WTP or WTA increases with the strength of the legal remedy, (2) negative types whose WTP or WTA decreases with the strength of the legal remedy, and (3) flat types whose WTP or WTA does not vary with the strength of the legal remedy. The existence of different types reduces the likelihood of a successful trade, since the heterogeneity of types makes it more difficult for Owner to predict Taker's WTA.

In our previous experiment, we have found that the complete absence of a property right (namely, an implicit right to take the owner's asset) did not have an adverse effect on trade and efficiency (Bar-Gill and Engel 2016). In a way, this experiment is an extension of our previous study, in that we allow for intermediate remedies, between complete and no protection of the original owner. Offering participants this richer action space changes the results. Since these are two separate experiments, we cannot directly compare outcomes. Still, juxtaposing the results of the two experiments, we hypothesize that by presenting subjects with a range of possible remedies we trigger a rich and heterogeneous spectrum of fairness norms, which interferes with efficient bargaining. But this explanation is only a conjecture, which requires further testing in the future.

Our results offer guidance to a policymaker tasked with determining the strength of the legal remedy. When the policymaker can verify which party attaches a higher value to the asset, she should simply allocate the asset to that party and choose the strongest, property rule remedy, which ensures efficiency without a need for bargaining. When the policymaker does not know which party attaches a higher value to the asset, the choice of remedy becomes more subtle. Specifically, the policymaker may want to choose a remedy that maximizes the probability of a successful deal. We find that more Owners are of negative type, whereas more Takers are positive types. This means that a weak remedy increases Owners' WTP and reduces Takers' WTA. Both effects work to increase the probability of a successful deal. We obtain a surprising result: Efficiency is maximized when entitlements are weakly protected. 


\section{References}

Abbink, Klaus, Gary E. Bolton, Abdolkarim Sadrieh and Fang-Fang Tang (2001). "Adaptive Learning versus Punishment in Ultimatum Bargaining." Games and Economic Behavior 37: 1-25.

Ai, Chunrong And Edward C. Norton (2003). "Interaction Terms in Logit and Probit Models." Economics Letters 80: 123-129.

Alterman, Rachelle (2010). Takings International. A Comparative Perspective on Land Use Regulations and Compensation Rights, American Bar Association.

AYRES, IAN (2005). Optional Law. The Structure of Legal Entitlements, University of Chicago Press.

BABCoCK, Linda And George Loewenstein (1997). "Explaining Bargaining Impasse. The Role of Self-Serving Biases." Journal of Economic Perspectives 11: 109-126.

Babcock, Linda, George loewenstein, Samuel Issacharoff and Colin F. Camerer (1995). "Biased Judgements of Fairness in Bargaining." American Economic Review 85: 1337-1343.

Balafoutas, Loukas, Martin G Kocher, Louis Putterman and Matthias Sutter (2013). "Equality, Equity and Incentives. An experiment." European Economic Review 60: 32-51.

Balliet, Daniel, Laetitia B Mulder and Paul AM Van Lange (2011). "Reward, Punishment, and Cooperation: A Meta-analysis." Psychological Bulletin 137(4): 594615.

BAR-Gill, Oren And Christoph Engel (2016). "Bargaining in the Absence of Property Rights. An Experiment." Journal of Law and Economics 59: 477-495.

Beckman, Steven R., John P. Formby and James W. Smith (2004). "Efficiency, Equity and Democracy. Experimental Evidence on Okun's Leaky Bucket." Research on Economic Inequality 11: 17-42.

Bereby-Meyer, Yoella And Muriel Niederle (2005). "Fairness in Bargaining." Journal of Economic Behavior \& Organization 56(2): 173-186.

Birmingham, Robert L (1970). "Breach of Contract, Damage Measures, and Economic Efficiency." Rutgers Law Review 24: 273-292.

Bock, Olaf, Ingmar Baetge And Andreas NicKlisch (2014). "hroot: Hamburg Registration and Organization Online Tool." European Economic Review 71: 117-120. 
Brosnan, Sarah F, Owen D Jones, Susan P Lambeth, Mary Catherine Mareno, AmanDA S Richardson AND Steven J SchapiRo (2007). "Endowment Effects in Chimpanzees." Current Biology 17(19): 1704-1707.

Calabresi, Guido and A. Douglas Melamed (1972). "Property Rules, Liability Rules and Inalienability. One View of the Cathedral." Harvard Law Review 85: 1089-1128.

Charness, Gary and ERnan Haruvy (2002). "Altruism, Equity, and Reciprocity in a GiftExchange Experiment. An Encompassing Approach." Games and Economic Behavior 40: 203-231.

Cherry, Todd L. AND JAson F. SHOGRen (2005). "Costly Coasean Bargaining and Property Right Security." Environmental and Resource Economics 31(3): 349-367.

CoOper, David J. And E. Glenn Dutcher (2011). "The Dynamics of Responder Behavior in Ultimatum Games. A Meta-study." Experimental Economics 14(4): 519-546.

Croson, Rachel T.A. And JAson ScotT Johnston (2000). "Experimental Results on Bargaining Under Alternative Property Rights Regimes." Journal of Law, Economics and Organization 16: 50-73.

EllsberG, DANiEl (1961). "Risk, Ambiguity, and the Savage Axioms." Quarterly Journal of Economics 75: 643-669.

Engel, Christoph, Sebastian Kube And Michael Kurschilgen (2016). Can we Manage First Impressions in Cooperation Problems? An Experiment. http://www.coll.mpg.de/pdf dat/2011 05online.pdf.

Engelmann, DirK And Martin Strobel (2004). "Inequality Aversion, Efficiency, and Maximin Preferences in Simple Distribution Experiments." American Economic Review 94: 857-869.

EPSTEIn, RichaRD A (2001). "Imperfect Liability Regimes. Individual and Corporate Issues." South California Law Review 53: 1153-1174.

FalK, Armin, ERnst Fehr And Urs Fischbacher (2003). "Reasons for Conflict. Lessons from Bargaining Experiments." Journal of Institutional and Theoretical Economics 159: $171-187$.

FALK, ARmin AND David Huffman (2007). "Studying Labor Market Institutions in the Lab. Minimum Wages, Employment Protection and Workfare." Journal of Institutional and Theoretical Economics 163: 30-45.

Fehr, ERnst And SimOn Gächter (2000). "Cooperation and Punishment in Public Goods Experiments." American Economic Review 90: 980-994. 
FeHR, ERnst And Simon GÄCHTER (2002). "Altruistic Punishment in Humans." Nature 415: 137-140.

FISCHBACHER, URS (2007). "z-Tree. Zurich Toolbox for Ready-made Economic Experiments." Experimental Economics 10: 171-178.

Friedmann, DANiEL (1989). "The Efficient Breach Fallacy." Journal of Legal Studies 18: 124.

Gilovich, Thomas and Victoria Husted Medvec (1995). "The Experience of Regret: What, When, and Why." Psychological Review 102(2): 379-395.

GNeEZy, URi AND Aldo Rustichini (2000). "A Fine is a Price." Journal of Legal Studies 29: $1-17$.

Goetz, Charles J And Robert E Scott (1977). "Liquidated Damages, Penalties and the Just Compensation Principle. Some Notes on an Enforcement Model and a Theory of Efficient Breach." Columbia Law Review 77(4): 554-594.

Gomez, Fernando And José S. Penalva (2008). Insurance and Tort: Coordination Systems And Imperfect Liability Rules. Internationalization of the Law and its Economic Analysis. T. Eger, C. Ott, J. Bigus and G. von Wangenheim. Heidelberg, 215-237.

GÜth, Werner, Rolf Schmittberger And Bernd Schwarze (1982). "An Experimental Analysis of Ultimatum Bargaining." Journal of Economic Behavior and Organization 3: 367-388.

HAisley, Emily C. AND RoBerto A. WeBer (2010). "Self-serving Interpretations of Ambiguity in Other-regarding Behavior." Games and Economic Behavior 68(2): 614-625.

Harrison, Glenn W., Elizabeth Hoffman, E. Elisabet Rutström and Matthew L. SPITZER (1987). "Coasian Solutions to the Externality Problem in Experimental Markets." Economic Journal 97(386): 388-402.

Harrison, Glenn W. AND Michael McKeE (1985). "Experimental Evaluation of the Coase Theorem." Journal of Law and Economics 28(3): 653-670.

Hoffman, Elizabeth and Matthew L. Spitzer (1982). "The Coase Theorem. Some Experimental Tests." Journal of Law and Economics 25(1): 73-98.

Hoffman, Elizabeth And Matthew L. Spitzer (1985). "Entitlements, Rights, and Fairness. An Experimental Examination of Subject's Concepts of Distributive Justice." Journal of Legal Studies 14: 259-297.

Holt, Charles A. AND Susan K. Laury (2002). "Risk Aversion and Incentive Effects." American Economic Review 92: 1644-1655. 
KAHNEMAN, DANIEL, JACK L. KNETSCH AND RiChARD THALER (1990). "Experimental Tests of the Endowment Effect and the Coase Theorem." Journal of Political Economy 98: 1325-1348.

Kahneman, Daniel, Jack L. KNetsch and Richard H. Thaler (1986). "Fairness as a Constraint on Profit Seeking. Entitlements in the Market." American Economic Review 76(4): 728-741.

Kahneman, Daniel, Jack L. Knetsch and Richard H. Thaler (1991). "Anomalies. The Endowment Effect, Loss Aversion, and Status Quo Bias." Journal of Economic Perspectives 5: 193-206.

Kaplow, Louis and Steven Shavell (1996). "Property Rules versus Liability Rules. An Economic Analysis." Harvard Law Review 109: 713-790.

Kelman, Mark (1978). "Consumption Theory, Production Theory, and Ideology in the Coase Theorem." Southern California Law Review 52: 669-698.

King, Ronald R. (1994). "An Experimental Investigation of Transaction Costs." Journal of Economic Behavior \& Organization 25(3): 391-409.

Konow, JAmes (2000). "Fair Shares. Accountability and Cognitive Dissonance in Allocation Decisions." American Economic Review 90(4): 1072-1091.

Köszegi, Botond And Matthew Rabin (2006). "A Model of Reference-Dependent Preferences." Quarterly Journal of Economics 121: 1133-1165.

Krier, JAMEs E AND StewART J SchwAB (1995). "Property Rules and Liability Rules. The Cathedral in Another Light." New York University Law Review 70: 440-483.

Lewinsohn-Zamir, Daphna (2001). "The Choice Between Property Rules and Liability Rules Revisited: Critical Observations from Behavioral Studies." Texas Law Review 80(2): 219-260.

LEWINSOHN-ZAMIR, DAPHNA (2012). "The Questionable Efficiency of the Efficient Breach Doctrine." Journal of Institutional and Theoretical Economics 168: 5-26.

Loewenstein, George, Samuel Issacharoff, Colin F. Camerer and Linda Babcock (1993). "Self-Serving Assessments of Fairness and Pretrial Bargaining." Journal of Legal Studies 22: 135-159.

Masclet, David, Charles Noussair and Marie-Claire Villeval (2013). "Threat and Punishment in Public Good Experiments." Economic Inquiry 51: 1421-1441.

McAdAms, Richard H. (2000a). "An Attitudinal Theory of Expressive Law." Oregon Law Review 79: 339-390. 
McAdams, Richard H. (2000b). "A Focal Point Theory of Expressive Law." Virginia Law Review 86: 1649-1729.

MCADAMS, Richard H. (2015). The Expressive Powers of Law. Harvard, Harvard University Press.

McAdams, Richard H. AND JANiCE NADler (2005). "Testing the Focal Point Theory of Legal Compliance. The Effect of Third-Party Expression in an Experimental Hawk/Dove Game." Journal of Empirical Legal Studies 2: 87-123.

NASH, John (1950). "The Bargaining Problem." Econometrica 18: 155-162.

Nikiforakis, Nikos S. And Hans-Theo Normann (2008). "A Comparative Statics Analysis of Punishment in Public Good Experiments." Experimental Economics 11: 358-369.

Norton, Roger D. And Robert H. Patrick (1985). "A Note on Prudencio's Experimental Tests of the Coase Propositions." Journal of Environmental Economics and Management 12(1): 96-100.

Polinsky, A. Mitchell (1979). "Controlling Externalities and Protecting Entitlements. Property Right, Liability Rule, and Tax-subsidy Approaches." Journal of Legal Studies 8(1): $1-48$.

Posner, Richard A. (2014). Economic Analysis of Law. New York, Aspen Publishers.

Prante, Tyler, Jennifer A. Thacher and Robert P. Berrens (2007). "Evaluating Coasean Bargaining Experiments with Meta-analysis." Economics Bulletin 3(68): 17.

Prudencio, Yves Coffi (1982). "The Voluntary Approach to Externality Problems: An Experimental Test." Journal of Environmental Economics and Management 9(3): 213228.

RACHLINSKI, JeFFRey J. AND Forest J. Jourden (1998). "Remedies and the Psychology of Ownership." Vanderbilt Law Review 51: 1541-1582.

Rammstedt, Beatrice and Oliver P. John (2007). "Measuring Personality in One Minute or Less. A 10-item Short Version of the Big Five Inventory in English and German." Journal of Research in Personality 41: 203-212.

Rhoads, Thomas A. And Jason F. Shogren (1999). "On Coasean Bargaining With Transaction Costs." Applied Economics Letters 6(12): 779-783.

SELTEN, ReInHARD (1967). Die Strategiemethode zur Erforschung des eingeschränkt rationalen Verhaltens im Rahmen eines Oligopolexperiments. Beiträge zur experimentellen Wirtschaftsforschung. E. Sauermann. Tübingen, Mohr: 136-168. 
SHAPIRO, CARL (2016). Property Rules vs. Liability Rules for Patent Infringement. https://ssrn.com/abstract=2775307.

Shogren, Jason F. (1998). "Coasean Bargaining with Symmetric Delay Costs." Resource and Energy Economics 20(4): 309-326.

Slonim, Robert And Alvin E. Roth (1998). "Learning in High Stakes Ultimatum Games. An Experiment in the Slovak Republic." Econometrica 66: 569-596.

Thaler, Richard H., Amos Tversky, Daniel Kahneman and Alan Schwartz (1997). "The Effect of Myopia and Loss Aversion on Risk Taking. An Experimental Test." Quarterly Journal of Economics: 647-661.

Treitel, Guenter H (1988). Remedies for Breach of Contract: A Comparative Account. Oxford, Oxford University Press.

Tversky, Amos and Daniel Kahneman (1991). "Loss Aversion in Riskless Choice. A Reference-Dependent Model." Quarterly Journal of Economics 106: 1039-1061. 


\section{Appendix Individual Choices}
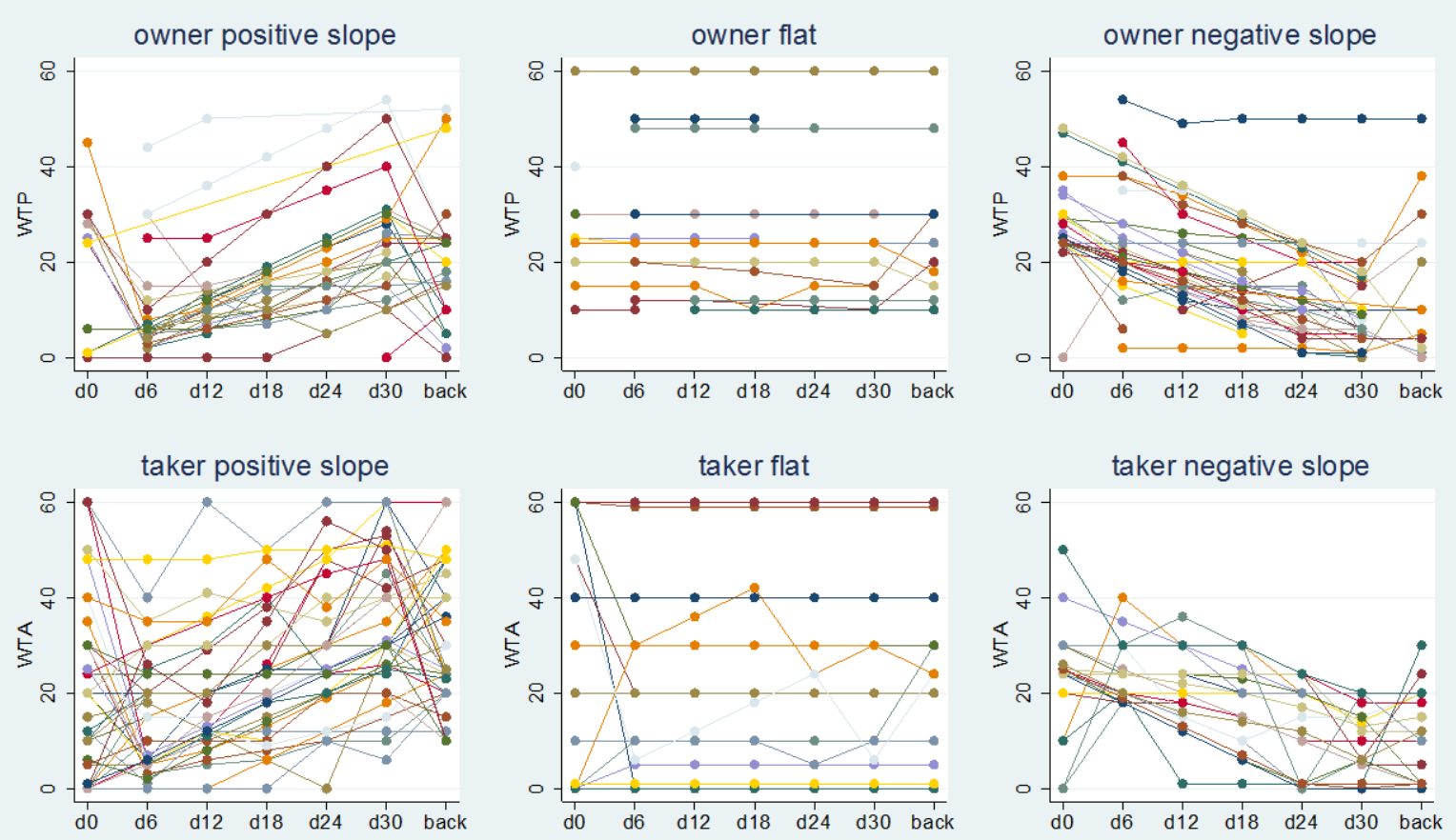

Figure 10

Willingness to Pay and Willingness to Accept from all Participants
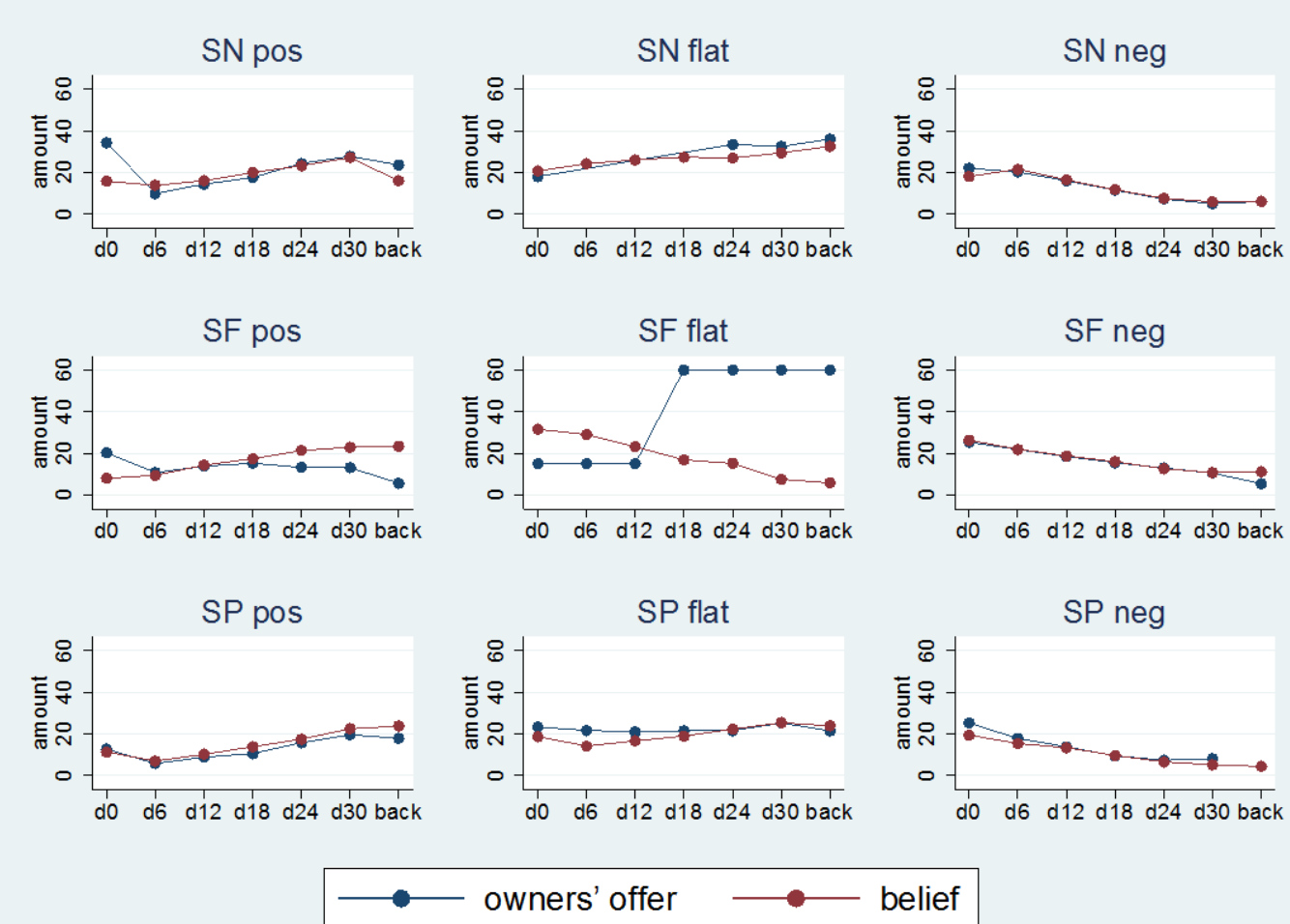

Figure 11

Owners' offers and beliefs by severity treatment and type 
SN pos

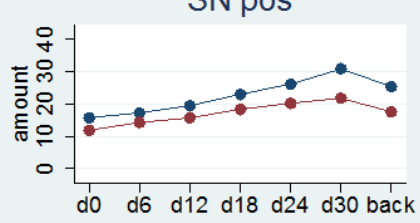

SF pos

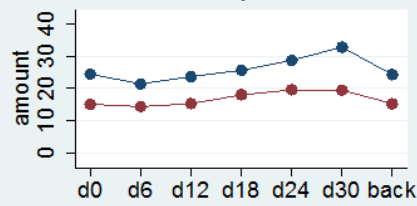

SP pos

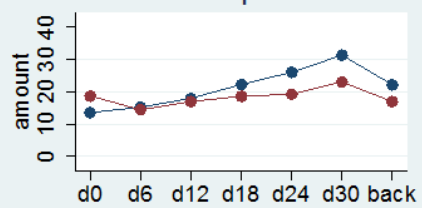

SN flat

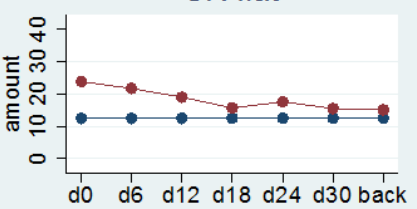

SF flat

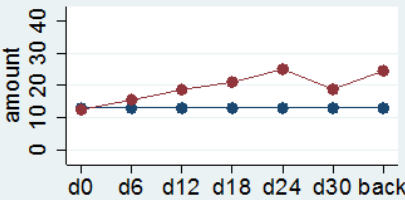

SP flat

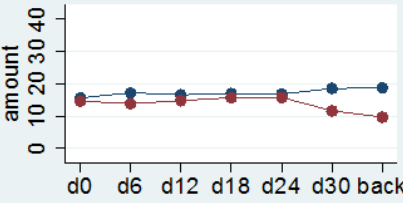

SN neg

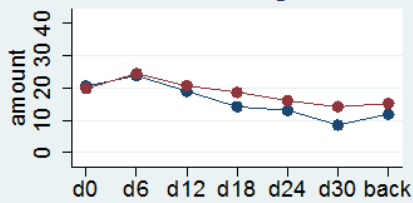

SF neg

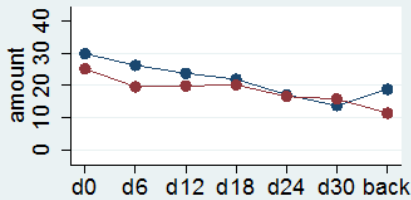

SP neg

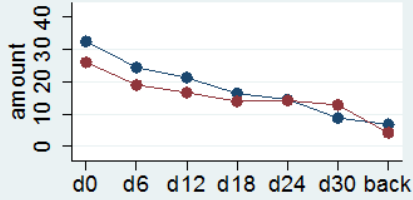

takers' offer $\longrightarrow$ belief

Figure 12

Takers' offers and beliefs by severity treatment and type

EN pos

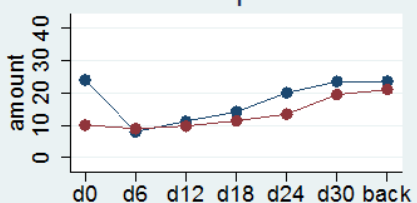

EF pos

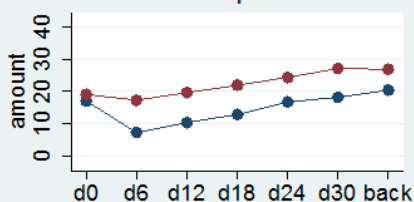

EP pos

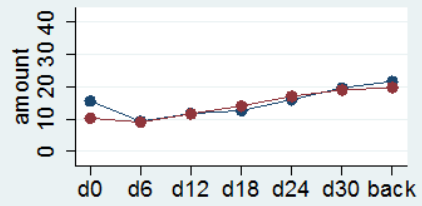

EN flat

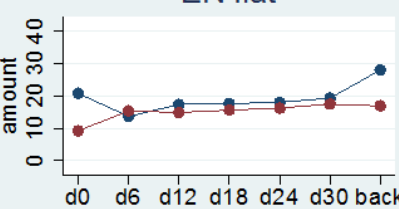

EF flat

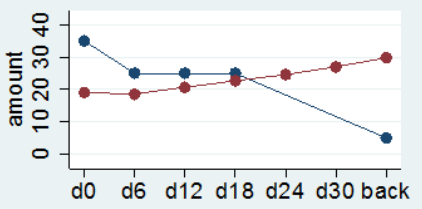

EP flat

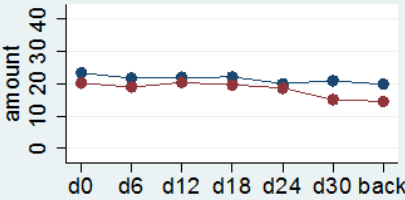

EN neg

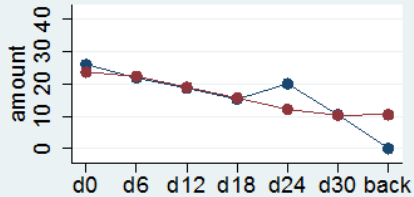

EF neg

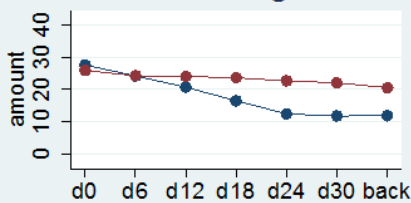

EP neg

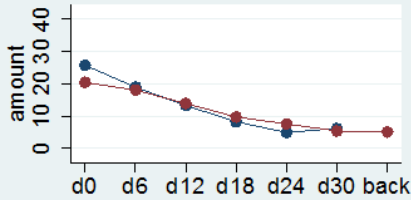

\section{$\longrightarrow$ owners' offer $\longrightarrow$ belief}

Figure 13

Owners' offers and beliefs by expressive treatment and type 


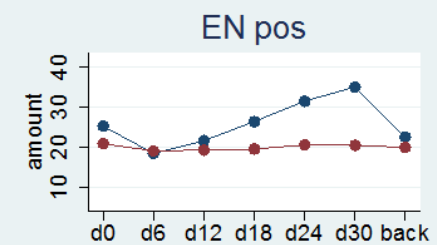

EN flat

EN neg
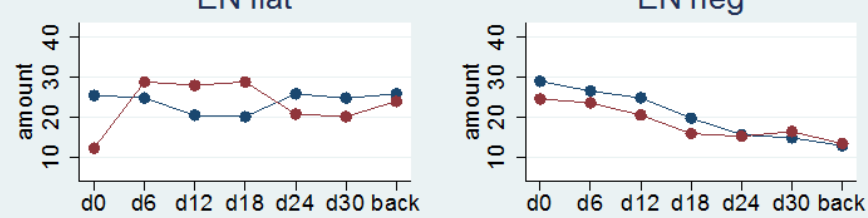

EF pos

EF flat

EF neg
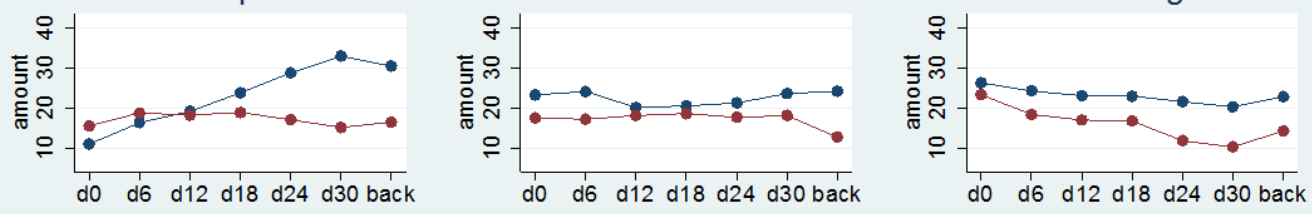

EP pos

EP flat

EP neg
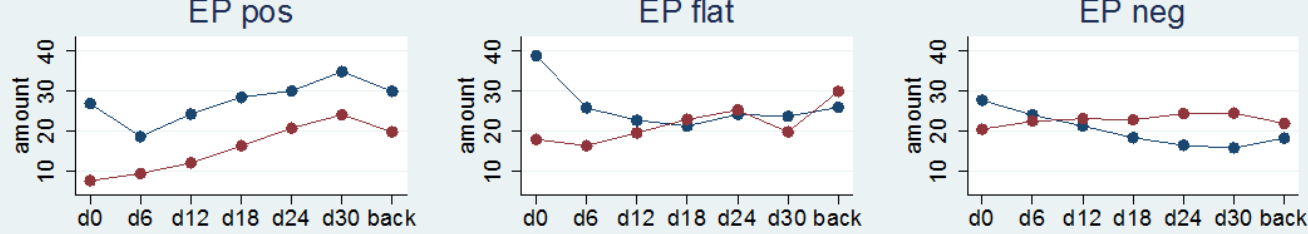

takers' offer

belief

Figure 14

Takers' offers and beliefs by expressive treatment and type 


\section{Instructions for the Main Experiment ${ }^{19}$}

\section{General Instructions}

You are now taking part in an experiment. If you read the following instructions carefully, you can, depending on your decisions, earn a considerable amount of money. It is therefore important that you take your time to understand the instructions.

Please do not communicate with the other participants during the experiment. Should you have any questions please ask us.

All your choices remain completely anonymous.

The experiment consists of five independent parts. Your decisions in one part of the experiment do not affect your payoffs and decisions in other parts of the experiment. In the following you receive the instructions for part 1 . You will receive instructions for the other parts of the experiment before the beginning of the respective part.

You will receive feedback on all parts of the experiment at its very end. It is at this point that we will inform you about your payoff from each part of the experiment.

In the first two parts of the experiment, we calculate your payoff in Experimental Currency Units (ECU). At the end of the experiment, we will convert 1 ECU into 10 Eurocent. Hence 1 $€$ corresponds to $10 \mathrm{ECU}$.

\section{[Part 1]}

Part 1 of the experiment is only played once and not repeated. You are randomly matched with one other anonymous participant. At the beginning of the experiment, both of you receive an endowment of 60 ECU (Experimental Currency Units). You are - again randomly - assigned a role. One of you will have role $A$, the other will have role $B$. There is one unit of a good. If, at the end of this part of the experiment, $A$ is in possession of the good, the experimenter buys the good from her at a price of $24 \mathrm{ECU}$. If, at the end of this part of the experiment, $B$ is in possession of the good, the experimenter buys the good from her at a price of $48 \mathrm{ECU}$.

Part 1 of the experiment has 5 stages. At stage 1, B earns this good. To that end, on the computer screen $B$ receives a series of 10x10 tables, filled with 0 s and $1 \mathrm{~s}$. B must correctly indicate the number of $1 \mathrm{~s}$ in 10 such tables. The following is an example of the task:

19 Instructions for the supplementary treatments are available from the authors upon request. 


\begin{tabular}{|l|l|l|l|l|l|l|l|l|l|}
\hline 0 & 0 & 1 & 1 & 1 & 0 & 0 & 1 & 0 & 0 \\
\hline 1 & 0 & 0 & 0 & 1 & 1 & 0 & 1 & 1 & 1 \\
\hline 1 & 0 & 1 & 0 & 1 & 0 & 0 & 0 & 1 & 0 \\
\hline 0 & 0 & 0 & 1 & 1 & 0 & 0 & 0 & 1 & 0 \\
\hline 1 & 0 & 0 & 0 & 1 & 1 & 0 & 1 & 1 & 1 \\
\hline 0 & 1 & 0 & 1 & 1 & 0 & 1 & 0 & 1 & 1 \\
\hline 1 & 1 & 1 & 1 & 0 & 0 & 0 & 1 & 0 & 1 \\
\hline 1 & 1 & 1 & 0 & 0 & 1 & 0 & 1 & 0 & 1 \\
\hline 0 & 1 & 0 & 1 & 0 & 0 & 1 & 1 & 0 & 0 \\
\hline 0 & 0 & 1 & 1 & 0 & 0 & 1 & 1 & 0 & 1 \\
\hline
\end{tabular}

At stage 4, A has a chance to take the good from B. At stage 2 and $3, A$ and B may conclude a binding contract. If a deal is struck, the agreed-upon contract would contain two elements: (i) A would give up the ability to take the good at stage 4, and, in exchange, (ii) B would pay A a sum between 0 and $60 \mathrm{ECU}$, as stipulated by the contract. A and B decide upon conclusion of a contract according to the following procedure: (1) At stage 2, B is allowed to offer a payment if A commits not to take the good at stage 4. (2) A decides at stage 3 whether she accepts or rejects. If she accepts, the price stated by the contract is transferred from $B$ to $A$. If $A$ rejects the offer (or if $B$ did not make an offer), at stage 4 A decides whether to take the good from B.

At stage 5 the computer randomly decides which of the following seven regimes applies. Each regime is equally likely to apply. In each regime, $B$ is entitled to the claim as specified in the following table, provided there is no contract and A has taken the good. These effects are automatic.

\begin{tabular}{|l|l|}
\hline regime & If A has taken the good, B may claim that \\
\hline 1 & computer transfers good back to B \\
\hline 2 & computer reduces A's payoff by $30 \mathrm{ECU}$ and transfers them to B \\
\hline 3 & computer reduces A's payoff by $24 \mathrm{ECU}$ and transfers them to B \\
\hline 4 & computer reduces A's payoff by $18 \mathrm{ECU}$ and transfers them to B \\
\hline 5 & computer reduces A's payoff by $12 \mathrm{ECU}$ and transfers them to B \\
\hline 6 & computer reduces A's payoff by $6 \mathrm{ECU}$ and transfers them to B \\
\hline 7 & B has no claim \\
\hline
\end{tabular}


The following is a schematic representation of the stages of the experiment:

\begin{tabular}{|l|l|l|}
\hline Stage & A & B \\
\hline 1 & - & earns good by correctly solving 10 tables \\
\hline 2 & & may offer contract \\
\hline 3 & $\begin{array}{l}\text { may accept contract } \\
\text { (if contract has been offered) }\end{array}$ & $\begin{array}{l}\text { may take good } \\
\text { (if no contract has been concluded) }\end{array}$ \\
\hline 4 & $\begin{array}{l}\text { at very end of experiment only } \\
\text { computer randomly chooses one of 7 regimes } \\
\text { computer executes choices participants have made for this regime } \\
\text { computer fulfills B's claim } \\
\text { (if A has taken the good and the regime gives B a claim) } \\
\text { computer gives feedback on choices and payoffs }\end{array}$ \\
\hline
\end{tabular}

As has just been stated, the relevant regime will only be defined at the very end of the entire experiment. We therefore ask you to make a choice for each of these seven regimes. Hence at stage 2, participant B will be asked whether she wants to make an offer, and if so which price she offers, for each of the seven regimes. To that end, we will show you a table at the computer screen.

Please indicate, separately for each regime, whether you want to offer $A$ that she commits not to take the good at stage 4, against payment as stipulated:

\begin{tabular}{|l|l|l|l|}
\hline regime & $\begin{array}{l}\text { If A has taken the good, B may } \\
\text { claim that }\end{array}$ & $\begin{array}{l}\text { do you want to } \\
\text { make an offer? } \\
\text { (yes/no) }\end{array}$ & $\begin{array}{l}\text { if you want to make an offer, } \\
\text { which price do you offer? } \\
\text { (between 0 and 60 ECU) }\end{array}$ \\
\hline 1 & $\begin{array}{l}\text { computer transfers good back to } \\
\text { B }\end{array}$ & & \\
\hline 2 & $\begin{array}{l}\text { computer reduces A's payoff by } \\
30 \text { ECU and transfers them to B }\end{array}$ & & \\
\hline 3 & $\begin{array}{l}\text { computer reduces A's payoff by } \\
24 \text { ECU and transfers them to B }\end{array}$ & & \\
\hline 4 & $\begin{array}{l}\text { computer reduces A's payoff by } \\
18 \text { ECU and transfers them to B }\end{array}$ & & \\
\hline 5 & $\begin{array}{l}\text { computer reduces A's payoff by } \\
12 \text { ECU and transfers them to B }\end{array}$ & & \\
\hline 6 & $\begin{array}{l}\text { computer reduces A's payoff by } \\
6 \text { ECU and transfers them to B }\end{array}$ & & \\
\hline 7 & B has no claim & & \\
\hline
\end{tabular}

A sees an equivalent table. Separately for each regime, she decides about the minimum offer she would accept. In a further column, she is asked: "If you are offered an amount below your minimum threshold, will you take the good?". 


\section{[Part 2]}

The second part of the experiment builds on the first. If you have had role $A$ in the first part of the experiment, on the computer screen you will learn how many participants, in this session, have held role B (half of the session), and you will be asked to fill in the following table

\begin{tabular}{|l|l|l|l|}
\hline regime & $\begin{array}{l}\text { If A has taken the good, B } \\
\text { may claim that }\end{array}$ & $\begin{array}{l}\text { how many participants } \\
\text { with role B have made } \\
\text { an offer? }\end{array}$ & $\begin{array}{l}\text { which price have those } \\
\text { who have made an offer } \\
\text { on average offered? }\end{array}$ \\
\hline 1 & $\begin{array}{l}\text { computer transfers good } \\
\text { back to B }\end{array}$ & & \\
\hline 2 & $\begin{array}{l}\text { computer reduces A's } \\
\text { payoff by 30 ECU and } \\
\text { transfers them to B }\end{array}$ & & \\
\hline 3 & $\begin{array}{l}\text { computer reduces A's } \\
\text { payoff by 24 ECU and } \\
\text { transfers them to B }\end{array}$ & & \\
\hline 4 & $\begin{array}{l}\text { computer reduces A's } \\
\text { payoff by 18 ECU and } \\
\text { transfers them to B }\end{array}$ & & \\
\hline 5 & $\begin{array}{l}\text { computer reduces A's } \\
\text { payoff by 12 ECU and } \\
\text { transfers them to B }\end{array}$ & & \\
\hline 6 & $\begin{array}{l}\text { computer reduces A's } \\
\text { payoff by 6 ECU and } \\
\text { transfers them to B }\end{array}$ & & \\
\hline 7 & B has no claim & & \\
\hline
\end{tabular}

You will be remunerated for one randomly selected answer. It will be the answer referring to the regime that the computer decides to be payoff relevant for part 1 of the experiment. With equal probability you will be remunerated for your answer to either of the two questions. If the question regarding the number of offers is payoff relevant, you will receive $3 \mathrm{ECU}$ if you got the number exactly right, and $1 \mathrm{ECU}$ if your answer was one below or above the exact answer. If the question regarding the size of the offer is payoff relevant, you will receive $3 \mathrm{ECU}$ if your answer is exact or no less than one below or above the exact answer. You will receive 1 ECU if your answer is no more than two below or above the exact answer.

If you have held role $B$ in the first part of the experiment, we tell you that participants who held role A were asked to specify the smallest offer that they would still accept. We ask you, separately for each of the 7 regimes, to estimate the smallest acceptable offer specified by the average role A participant (see table below). If the size of the offer you indicate is no further away from the true average than $1 \mathrm{ECU}$, you receive $3 \mathrm{ECU}$. If your answer is no further away than $2 \mathrm{ECU}$ from the true average, you receive $1 \mathrm{ECU}$. 


\begin{tabular}{|l|l|l|}
\hline regime & $\begin{array}{l}\text { If A has taken the good, B may } \\
\text { claim that }\end{array}$ & $\begin{array}{l}\text { What is the smallest acceptable offer, spe- } \\
\text { cified by the average role A participant? }\end{array}$ \\
\hline 1 & computer transfers good back to B & \\
\hline 2 & $\begin{array}{l}\text { computer reduces A's payoff by } 30 \\
\text { ECU and transfers them to B }\end{array}$ & \\
\hline 3 & $\begin{array}{l}\text { computer reduces A's payoff by 24 } \\
\text { ECU and transfers them to B }\end{array}$ & \\
\hline 4 & $\begin{array}{l}\text { computer reduces A's payoff by 18 } \\
\text { ECU and transfers them to B }\end{array}$ & \\
\hline 5 & $\begin{array}{l}\text { computer reduces A's payoff by 12 } \\
\text { ECU and transfers them to B }\end{array}$ & \\
\hline 6 & $\begin{array}{l}\text { computer reduces A's payoff by } 6 \\
\text { ECU and transfers them to B }\end{array}$ & \\
\hline 7 & B has no claim \\
\hline
\end{tabular}

